\title{
LA APLICACIÓN PÚBLICA DE LAS NORMAS DE LIBRE COMPETENCIA EN LA COMUNIDAD ANDINA Y SUS PAÍSES INTEGRANTES*
}

\author{
THE PUBLIC ENFORCEMENT IN THE \\ ANDEAN COMMUNITY COMPETITION \\ LAWS AND THEIR MEMBERS SYSTEMS
}

\author{
Ingrid S. Ortiz-Baquero** \\ Diego A. Solano-Osorio**** \\ Fecha de recepción: 28 de septiembre de 2015 \\ Fecha de aceptación: 10 de mayo de 2016 \\ Disponible en linea: 31 de mayo de 2016
}

\section{Para citar este artículo/To cite this article}

\author{
Ortiz-Baquero, Ingrid S. \& Solano-Osorio, Diego A., La aplicación públi- \\ ca de las normas de libre competencia en la Comunidad Andina y sus países \\ integrantes, 132 Vniversitas, 311-348 (2016). http://dx.doi.org/10.11144/ \\ Javeriana.vj132.apnl \\ doi:10.11144/Javeriana.vj132.apnl
}

* Este artículo hace parte del proyecto de investigación La aplicación privada o judicial de las normas de libre competencia en la Comunidad Andina de Naciones y sus países integrantes, llevado a cabo por el Grupo de Investigación de Derecho Comercial de la Universidad Externado de Colombia.

** Abogada, especialista en Derecho comercial y magíster en responsabilidad contractual y extracontractual civil y del Estado, Universidad Externado de Colombia. Diploma de estudios avanzados en derecho mercantil y doctora en derecho mercantil, Universidad Autónoma de Madrid, UAM. Magíster en derecho y economía del consumo, Universidad de Castilla-La Mancha, UCLM. Docente investigadora, Universidad Externado de Colombia. Contacto: ingrido.ortiz@uexternado.edu.co

*** Abogado y especialista en derecho comercial, Universidad Externado de Colombia. Asistente de investigación y asistente en la cátedra de comercial quinto año, Títulos Valores, Universidad Externado de Colombia. Contacto: diego.solano@uexternado.edu.co 


\section{RESUMEN}

La introducción de la aplicación privada o private enforcement en los diferentes sistemas jurídicos de derecho de la competencia presentes en el mundo, se ha dado tras un largo y consolidado desarrollo de la aplicación pública o public enforcement, que ve las acciones de daños como su complemento, más allá de considerarlas como su detractor. En este sentido, el presente documento pretende analizar el sistema público de cumplimiento de las normas del derecho de la competencia preponderante tanto en la Comunidad Andina, como en sus países integrantes $\mathrm{y}$, de esta manera, identificar sus elementos característicos y evaluar las ventajas que ha traído a estos países el mantenimiento de este sistema.

Palabras clave: aplicación privada; aplicación pública; Comunidad Andina; acción de daños; derecho de la competencia 


\section{ABSTRACT}

The introduction of private enforcement in the different Competition Law legal systems, has been after a long and consolidated development of public enforcement, which see damages actions as a complement, rather than considering it as its detractor. In this sense, this article pretends to analyze the public enforcement in the Andean Community and their members, in order to identify their main characteristics, and to evaluate the advantages to keeping the application of this model.

Keywords: Private enforcement; public enforcement; Andean Community; damage actions; competition law

\section{SUMARIO}

INTRODUCCIÓN.- I. PANORAMA GENERAL DEL DERECHO DE LA LIBRE COMPETENCIA EN LA CAN Y SUS PAÍSES INTEGRANTES.- II. UNA VISIÓN GENERAL DE LA APLICACIÓN PÚBLICA DE LAS NORMAS DE LIBRE COMPETENCIA.- $A$. El modelo comunitario andino.- $B$. La experiencia en el modelo público de aplicación de las normas de libre competencia.- CONCLuSIONES.- BiBliogRAFía. 


\section{INTRODUCCIÓN}

Históricamente, la aplicación de las normas de libre competencia ha seguido dos modelos: uno de carácter público o administrativo con raíces en el sistema de derecho europeo continental y un modelo privado o judicial - también llamado private enforcement-que tiene su origen y su mayor evolución en el sistema jurídico estadounidense ${ }^{1}$.

En el modelo público, la aplicación de las normas de libre competencia (también denominadas en este escrito normas antitrust) corresponde por regla general a autoridades administrativas que tienen la capacidad de actuar de oficio o a petición de parte, pero siempre en defensa del orden público económico; mientras en el modelo privado son los particulares por medio de las acciones civiles, fundamentalmente las acciones de daños, los encargados de promover la aplicación de las normas de libre competencia ${ }^{2}$.

Quienes defienden el modelo público o administrativo señalan que este permite un mayor control de las conductas que afectan de forma más grave la libre competencia, esto es, los carteles duros (acuerdos de precios y distribución de mercados, comoquiera que se mantiene en la esfera de las autoridades públicas la carga de demostrar la infracción y de imponer las sanciones respectivas). Asimismo, se afirma que es un modelo que responde de forma más efectiva a la protección del interés público económico en la medida en que no condiciona la intervención de la autoridad de competencia a la existencia de un daño o a la lesión de un interés particular ${ }^{3}$.

1 Assimakis Komninos, EC Private Antitrust Enforcement. Decentralised Application of EC Competition Law by National Courts, 2 (Hart Publishing, Oxford, Portland, Oregon, 2008). KomNINOs define el private enforcement en los siguientes términos: "As a consequence, private enforcement is defined more appropriately by reference to litigation, in which private parties advance independent civil claims or counterclaims based on the EC [European Commission] competition provisions. Such a definition would basically cover civil litigation, but it would be broad enough to encompass third party civil claims attached to civil and/or administrative public enforcement proceedings".

2 Sobre el comparativo entre el private y public enforcement, Randolph Preston McAfee, Hugo Marc Mialon \& Sue H. Mialon, Private v. Public Antitrust Enforcement: A Strategic Analysis, 92 Journal of Public Economics, 10/11, 1863-1875 (2008).

3 "The divergence between the objectives of both types of enforcement is manifest if we focus on the dissuasive purpose of the sanctions. A company that has been victim of an anticompetitive action and whose losses are irrecoverable would wish to enter into proceedings only if it could obtain compensation for the harm suffered. On the other hand, a public agency will pursue the case given the demonstrative effect of the sanction on anticompetitive actions, and its future dissuasive impact. As pointed out by Ilya Segal and Michael Whinston, public 
Por su parte, los defensores del modelo privado indican que (i) Las sanciones administrativas y económicas no siempre logran cumplir una función disuasoria de las conductas restrictivas de la competencia; (ii) Las víctimas son quienes en mejor medida pueden demostrar la existencia de la conducta ilícita; y (iii) Un sistema público no permite el resarcimiento efectivo de los daños padecidos, lo cual deja a los perjudicados por las conductas anticompetitivas en una situación de total desprotección.

Este debate en torno a cuál es el modelo de aplicación de las normas de libre competencia que resulta más adecuado y más eficiente no ha sido resuelto ni por la doctrina estadounidense ni tampoco por la europea ${ }^{4}$. En general, puede afirmarse que aquellos puntos que parecen ventaja desde la perspectiva del modelo público resultan ser objeto de crítica por quienes abogan por la necesidad de la intervención judicial en esta materia, y, contrario sensu, los

enforcement, by focusing more on dissuasion, is forward-looking and, therefore, has a greater commitment to initiate proceedings, including in those cases where competitive damage is irreversible. It is noteworthy that companies may also wish to act as forward-looking by building a reputation for being aggressive toward anticompetitive acts. Notwithstanding, it is likely for the reputation effect to be stronger for public agencies than for private companies. To dissuade similar practices in all industries is part of the objective function of the public agency, whereas a company will focus solely on itself”. Aldo González \& Alejandro Micco, Private versus Public Antitrust Enforcement: Evidence from Chile, 10 Journal of Competition Law \& Economics, 3, 691-709. Disponible en: http://lacer.lacea.org/bitstream/handle/123456789/53161/ lacea2015_private_versus_public.pdf?sequence $=1$

4 Sobre el particular, la Directiva 2014/104 del Parlamento Europeo permite vislumbrar la intención de la Comunidad Europea de la protección de la libre competencia por medio de los dos sistemas: "La aplicación pública de los artículos 101 y 102 del TFUE [Tratado de Funcionamiento de la Unión Europea] es responsabilidad de la Comisión, que hace uso de las facultades que le confiere el Reglamento (CE) 1/2003 del Consejo. Desde la entrada en vigor del Tratado de Lisboa el 1 de diciembre de 2009, los artículos 81 y 82 del Tratado constitutivo de la Comunidad Europea son ahora los artículos 101 y 102 del TFUE y permanecen sustancialmente idénticos. Las autoridades nacionales de la competencia, que pueden adoptar las decisiones que figuran en el artículo 5 del Reglamento (CE) 1/2003, también se encargan de dicha aplicación pública. De conformidad con ese Reglamento, los Estados miembros deben poder designar autoridades administrativas y judiciales para que apliquen los artículos $101 \mathrm{y}$ 102 del TFUE en calidad de encargados de velar por su aplicación pública y para que lleven a cabo las distintas funciones que dicho Reglamento confiere a las autoridades de la competencia". A continuación, expone: "Los artículos 101 y 102 del TFUE producen efectos directos en las relaciones entre particulares y generan, para los afectados, derechos y obligaciones que los órganos jurisdiccionales nacionales deben aplicar. Por tanto, los órganos jurisdiccionales nacionales también tienen una función esencial en la aplicación de las normas sobre competencia (la aplicación privada)". Parlamento Europeo, Consejo de la Unión Europea, Directiva 2014/104 del Parlamento Europeo, 26 de noviembre de 2014, relativa a determinadas normas por las que se rigen las acciones por daños en virtud del derecho nacional, por infracciones del derecho de la competencia de los Estados miembros y de la Unión Europea, L349 Diario Oficial de la Unión Europea, 5 de diciembre de 2014. Disponible en: http://eur-lex.europa.eu/ legal-content/ES/TXT/?uri=CELEX\%3A32014L0104 
beneficios del modelo de aplicación privada son los puntos objeto de crítica por parte de sus detractores ${ }^{5}$.

A nuestro juicio, no obstante la larga trayectoria del debate, el tema tiene hoy una especial importancia - en particular en la esfera de los países latinoamericanos - ya no para señalar la vigencia o preponderancia de un modelo sobre otro, sino para establecer los mecanismos que permitirían lograr la coexistencia y el funcionamiento armónico de un sistema público junto con las acciones de daños y la intervención de los jueces. El reto es aprovechar las ventajas de cada sistema o modelo de aplicación y coordinar la intervención de las autoridades tanto administrativas como judiciales con el fin de obtener una mayor aplicación de las normas de competencia en los distintos sectores del mercado, lograr una disuasión efectiva de las conductas restrictivas y resarcir a las víctimas de los daños derivados de las conductas anticompetitivas.

Hechas estas consideraciones generales, en este artículo nos referiremos a la aplicación de las normas de competencia en el ámbito de los países que integran la Comunidad Andina (en adelante, CAN) y al modelo que actualmente se sigue en el contexto comunitario andino. Con este fin, realizaremos un análisis descriptivo de las principales características que posee este modelo y, con ello, en la segunda parte de la investigación, haremos un análisis comparativo de las ventajas y desventajas de ambos modelos de aplicación.

5 Sobre los factores de comparación entre la aplicación pública y privada de las normas de libre competencia, es posible consultar, entre muchos otros: JACOB RüGgeBerg \& MAARTEN PIETER Schinkel, Consolidating Antitrust Damages in Europe: A Proposal for Standing in Line with Efficient Private Enforcement, 1-25 (Universiteit von Amsterdam, Amsterdam Center for Law \& Economics, Working Paper 2006-04, 2006). Disponible en: http://papers.ssrn.com/sol3/ papers.cfm?abstract_id=903282. Hay una versión más reciente del trabajo de MAARTEN PIETER SCHInkel, Effective Cartel Enforcement in Europe, 30 World Competition: Law and Economics Review, 4, 539-572 (2007) (Universiteit von Amsterdam, Amsterdam Center for Law \& Economics, Working Paper 2006-14, 2006). Disponible en: http://papers.ssrn.com/sol3/papers. cfm?abstract_id=948641. Robert H. LANde \& Joshua P. Davis, Benefits from Private Antitrust Enforcement: An Analysis of Forty Cases, 42 University of San Francisco Law Review, 879-918 (2008). Disponible en: http://papers.ssrn.com/sol3/papers.cfm?abstract_id=1090661. WoUTER P. J. WILs, Should Private Antitrust Enforcement Be Encouraged in Europe?, 26 World Competition, Law and Economics Review, 3, 473-488, 476-477 (2003). Disponible en: http://papers. ssrn.com/sol3/papers.cfm?abstract_id=1540006, https://www.researchgate.net/profile/Wouter_ Wils/publication/228261623_Should_Private_Antitrust_Enforcement_Be_Encouraged_ in_Europe/links/004635346539e943bc000000.pdf/download?version=vs. ILYA R. SEGAL \& MIChael D. Whinston, Public vs. Private Enforcement of Antitrust Law: A Survey, 1-17 (Stanford Law and Economics Olin, Working Paper 335, 2008). Disponible en: http://papers.ssrn.com/ sol3/papers.cfm?abstract_id=952067 


\section{Panorama general del derecho DE LA LIBRE COMPETENCIA EN LA CAN Y SUS PAÍSES INTEGRANTES}

El derecho de la libre competencia o de defensa de la competencia en América Latina tiene una historia reciente. Aunque los primeros pasos en este ámbito del derecho se dieron de la mano de la legislación y la experiencia estadounidense, hoy la legislación de los países latinoamericanos se nutre de forma más intensa de los avances y desarrollos del derecho comunitario europeo ${ }^{6}$.

Es importante recordar que no obstante las primeras normas de libre competencia en Latinoamérica fueron aprobadas a comienzos del siglo pasado, solo puede hablarse de un verdadero desarrollo de la materia cuando se emprende el proceso de sustitución de las políticas económicas proteccionistas y se dan los primeros pasos para la implementación del modelo neoliberal, reformas estas coincidentes con los primeros acuerdos de integración subregional ${ }^{7}$.

Así las cosas, cabe afirmar que los primeros avances concretos en esta materia se sitúan a comienzos de los años $1990^{8}$, cuando

6 Prueba de esta nueva fuente de apoyo y conocimiento son los acuerdos de colaboración suscritos entre la Unión Europea y la CAN cuyo resultado más notable ha sido la aprobación de la Decisión 608/2005. Comisión de la Comunidad Andina, CAN, Decisión 608/2005, Normas para la protección y promoción de la libre competencia en la Comunidad Andina, Lima, Perú, 28 de marzo de 2005. Disponible en: http://intranet.comunidadandina.org/Documentos/ decisiones/DEC608.doc

7 Al respecto, Osvaldo Rosales, Integración regional: propuestas de renovación, en Paradojas de la Integración en América Latina y el Caribe, 33-66 (Josette Altmann, Francisco RojasAravena, eds., Facultad Latinoamericana de Ciencias Sociales, FLACSO, Organización de Naciones Unidas, ONU, Comisión Económica para América Latina y el Caribe, CEPAL, Fundación Carolina de España, Siglo XXI Editores, 2008). Además, Pedro CAnovas, Planteamientos de la integración. Evolución de la integración en Latinoamérica, en III Simposio Grupo de Estudios Jean Monnet, ponencia, Madrid, 7-8 de marzo de 2002, 19-35 (2002). Disponible en: http://pendientedemigracion.ucm.es/BUCM/cee/cjm/0201/0203.pdf

8 Un análisis sobre la regulación de las conductas anticompetitivas (colusorias y abusivas) y las fusiones y adquisiciones en Latinoamérica durante los años 1990 y sobre las influencias recibidas del derecho estadounidense en este campo, puede verse en: Marcelo Celani \& LeONARdo Stanley, Defensa de la competencia en Latinoamérica: aplicación sobre conductas y estrategias, 28 Serie Estudios y Perspectivas, 1-64, 61 (Organización de Naciones Unidas, ONU, Comisión Económica para América Latina y el Caribe, CEPAL, Oficina de Buenos Aires, Santiago de Chile, 2005). Disponible en: http://www.cepal.org/es/publicaciones/4851defensa-de-la-competencia-en-latinoamerica-aplicacion-sobre-conductas-y. En relación con el ordenamiento jurídico colombiano, Carlos Andrés Perilla-Castro señala: "Desde la expedición de la Ley 155 de 1959, Colombia dispone de una ley en contra de las prácticas comerciales restrictivas. Sin embargo, hasta principios de la década de los noventa, esta ley fue inaplicada por las autoridades nacionales. Esta omisión podría atribuirse, entre otras razones, a los mecanismos de sustitución de importaciones y control de precios que durante 
en la mayoría de los países latinoamericanos se adelantaron reformas legislativas para promover el desarrollo de los procesos de privatización y liberalización de diversos sectores económicos. En la mayoría de los casos, estas reformas fueron aprovechadas para incluir y/o modernizar la normativa sobre protección y promoción de la libre competencia.

En los países que conforman la CAN, el proceso que hemos descrito solo tuvo lugar en los casos de Colombia y Perú, que durante la década de los años 1990 reforzaron su normativa nacional de libre competencia mediante la aprobación del Decreto 2153 de 1992 (en adelante, Decreto 2153/1992) y del Decreto Ley 701 de 1991 (en adelante, DL 701/1991), respectivamente9.

La situación de Bolivia y de Ecuador era distinta. En Bolivia, las normas de libre competencia estaban incluidas en las normas de carácter sectorial que se habían expedido a consecuencia de los procesos de liberalización de los servicios públicos, las telecomunicaciones y los hidrocarburos; y Ecuador no disponía de ninguna regulación sobre la materia.

Actualmente, el panorama normativo de los Estados integrantes de la CAN afronta una fase de grandes cambios provenientes de las recientes reformas y modernizaciones legislativas, de la aprobación de las nuevas normas de competencia, de los retos que imponen a los países andinos los acuerdos comerciales bilaterales y multilaterales, y de los avances en esta área en países como Brasil, Chile y Argentina ${ }^{10}$.

años escudaron la industria nacional de una efectiva competencia". CARlos AndRÉs PerillaCAStro, Propuestas para la protección de la libre competencia ante los jueces civiles, 21 Boletín Latinoamericano de Competencia, 2, 20-28, 20 (febrero de 2006). Disponible en: http://ec.europa. eu/competition/publications/blc/boletin_21_2.pdf

9 Colombia, Decreto 2153 de 1992, por el cual se reestructura la Superintendencia de Industria y Comercio y se dictan otras disposiciones, 40.704 Diario Oficial, 31 de diciembre de 1992. Disponible en: http://www.secretariasenado.gov.co/senado/basedoc/decreto_2153_1992.html. Perú, Decreto Ley 701 de 1991, eliminan las prácticas monopólicas, controlistas y restrictivas de la libre competencia, 5 de noviembre de 1991, Diario Oficial El Peruano, 7 de noviembre de 1991. Disponible en: http://www.sice.oas.org/compol/natleg/Peru/701.asp. La normativa de libre competencia en Colombia se puede consultar en la Superintendencia de Industria y Comercio, SIC: www.sic.gov.co. La normativa peruana puede consultarse en el Instituto Nacional de Defensa de la Competencia y de la Protección de la Propiedad Intelectual, INDECOPI: https://www.indecopi.gob.pe/web/defensa-de-la-libre-competencia/legislacion

10 Esta etapa de reformas es un eco del proceso de modernización de las normas de competencia europeas que culminó con la aprobación del Reglamento 1/2003 y de las normas que conforman el paquete de modernización. Consejo de la Unión Europea, Reglamento (CE) 1/2003 del Consejo, de 16 de diciembre de 2002, relativo a la aplicación de las normas sobre competencia 
En efecto, Perú ha modernizado su régimen de libre competencia mediante el Decreto Legislativo 1033 de 25 de junio de 2008, que aprueba la ley de organización y funciones del Instituto Nacional de Defensa de la Competencia y de la Protección de la Propiedad Intelectual, INDECOPI y del Decreto Legislativo 1034 de 25 de junio de $2008^{11}$, que aprueba la Ley de represión de conductas anticompetitivas. Colombia también ha modernizado su normativa con la Ley 1340 de 24 de julio de 2009, por medio de la cual se dictan normas en materia de competencia (en adelante, Ley 1340/2009) y de sus decretos reglamentarios ${ }^{12}$. Por su parte, Bolivia ha puesto en marcha sus primeras normas generales de competencia - Decreto Supremo 29519, de 16 de abril de $2008^{13}$ - y Ecuador afronta los retos propios de la aprobación de su Ley Orgánica de Regulación y Control del poder del Mercado ${ }^{14}$.

previstas en los artículos 81 y 82 del Tratado, L1 Diario Oficial de las Comunidades Europeas, 4 de enero de 2003. Disponible en: http://eur-lex.europa.eu/LexUriServ/LexUriServ.do?uri= OJ:L:2003:001:0001:0025:ES:PDF

11 Perú, Decreto Legislativo 1033, que aprueba la ley de organización y funciones del Instituto Nacional de Defensa de la Competencia y de la Protección de la Propiedad Intelectual, INDECOPI, Diario Oficial El Peruano, 25 de junio de 2008. Disponible en: https://www.indecopi. gob.pe/documents/20182/143803/d11033.pdf. Perú, Decreto Legislativo 1034, que aprueba la Ley de Represión de Conductas Anticompetitivas, Diario Oficial El Peruano, 25 de junio de 2008. Disponible en: https://www.indecopi.gob.pe/documents/51771/196578/d11034.pdf/66c0472e46de-4eb3-b872-7369c5279583. Recientemente modificado por el Decreto Legislativo 1205 de 2015. Perú, Decreto Legislativo 1205 de 2015, que modifica el Decreto Legislativo 1034 de 2008, que aprueba la ley de represión de conductas anticompetitivas, Diario Oficial El Peruano, 23 de setiembre de 2015. Disponible en: http://www.elperuano.com.pe/Normas Elperuano/2015/09/23/1290959-5.html

12 Colombia, Ley 1340 de 2009, por medio de la cual se dictan normas en materia de protección de la competencia, 47.420 Diario Oficial, 24 de julio de 2009. Disponible en: http://www. secretariasenado.gov.co/senado/basedoc/ley_1340_2009.html. Colombia, Decreto $1523 \mathrm{de}$ 2015 , por medio del cual se reglamenta el artículo 14 de la Ley 1340 de 2009 y se modifica el Capítulo 29 del Título 2 de la Parte 2 del Libro 2 del Decreto Único Reglamentario del Sector Comercio, Industria y Turismo, Decreto 1074 de 2015, sobre beneficios a las personas naturales y jurídicas que colaboren en la detección y represión de acuerdos restrictivos de la libre competencia, 49.575 Diario Oficial, 16 de julio de 2015. Disponible en: http://www. alcaldiabogota.gov.co/sisjur/normas/Norma1.jsp?i=62539. Colombia, Decreto 2897 de 2010, por medio del cual se reglamenta el artículo 7 de la Ley 1340 de 2009, 47.792 Diario Oficial, 5 de agosto de 2010. Disponible en: http://www.alcaldiabogota.gov.co/sisjur/normas/Norma1. jsp?i=40098

13 Bolivia, Decreto Supremo 29519, que regula la competencia y la defensa del consumidor frente a conductas lesivas, 16 de abril de 2008. Disponible en: http://www.autoridadempresas.gob. $\mathrm{bo} / \mathrm{marco}-\mathrm{legal} / \mathrm{decretos}$-supremos. Sobre la incompatibilidad de este régimen legal con la Decisión 608/2005, Mauricio OChOA-Urioste, Régimen General del Derecho de la Competencia en Bolivia -Decreto Supremo No. 29519—, 26 Boletín Latinoamericano de Competencia, 8-22 (2009). Disponible en: http://ec.europa.eu/competition/publications/blc/boletin_26.pdf

14 Ecuador, Ley Orgánica de Regulación y Control del Poder del Mercado, Registro Oficial, Suplemento 555, 13 de octubre de 2011. Disponible en: http://www.planificacion.gob.ec/wpcontent/uploads/downloads/2012/10/Ley-Organica.pdf. Sobre las causas que durante muchos 
En la Comunidad Andina, las primeras normas que regularon la protección de la libre competencia fueron las Decisiones de la Comisión del Acuerdo de Cartagena (en adelante, CAC) 45 de 1971 y 230 de $1987^{15}$. La aplicación de estas normas fue prácticamente nula, debido a la carencia de herramientas destinadas a su cumplimiento, y al desconocimiento sobre la importancia y la utilidad de esta normativa. Posteriormente, se aprobó la Decisión 285 de la CAC, de 21 de marzo de 1991 (en adelante, Decisión 285/1991), que por primera vez reguló de manera independiente, del dumping y de las restricciones a las exportaciones, las conductas restrictivas de la competencia. Infortunadamente, esta decisión tampoco tuvo la acogida ni logró la aplicación y el desarrollo que de ella se esperaba ${ }^{16}$. El gran salto regulatorio en la CAN se produjo con la aprobación de la Decisión 608/2005 de la Comisión de la Comunidad Andina (en adelante, Decisión 608/2005) que derogó y reemplazó la Decisión 285/1991. Esta norma modernizó la regulación de los acuerdos y actos restrictivos, confirió poderes e instrumentos a las autoridades supranacionales para la imposición de sanciones en casos de infracción, y sobre todo mitigó en su momento la carencia de una normativa general de libre de competencia tanto en Ecuador como en Bolivia, al establecer como obligatoria la aplicación de

años impidieron la expedición de una norma de libre competencia en Ecuador, FrANCISCO Marcos, ¿Una política de competencia para la República de Ecuador?, 21 Boletín Latinoamericano de Competencia, 2, 29-39 (febrero de 2006). Disponible en: http://ec.europa.eu/competition/ publications/blc/boletin_21_2.pdf

15 Comisión del Acuerdo de Cartagena, CAC, Decisión 45 de 1971, normas para prevenir o corregir las prácticas que puedan distorsionar la competencia dentro de la subregión, Lima, Perú, 9-18 de diciembre de 1971. Disponible en: http://intranet.comunidadandina.org/Documentos/ decisiones/DEC045.doc. Comisión del Acuerdo de Cartagena, CAC, Decisión 230 de 1987, normas para prevenir o corregir las prácticas que puedan distorsionar la competencia dentro de la Subregión. Sustitución de la Decisión 45, Lima, Perú, 10-11 de diciembre de 1987. Disponible en: http://intranet.comunidadandina.org/Documentos/decisiones/DEC230.doc

16 Además de la Decisión 285 de 1991, ese mismo año se expidieron las Decisiones 283, 284. El texto de las normas, decisiones y resoluciones andinas se encuentra disponible en la web: http://www.comunidadandina.org/normativa.htm. Comisión del Acuerdo de Cartagena, CAC, Decisión 283, normas para prevenir o corregir las distorsiones en la competencia generadas por prácticas de dumping o subsidios, Lima, Perú, 21-22 de marzo de 1991. Disponible en: http://www.sice.oas.org/antidumping/legislation/andina/dec283_s.asp. Comisión del Acuerdo de Cartagena, CAC, Decisión 284, normas para prevenir o corregir las distorsiones en la competencia generadas por restricciones a las exportaciones, Lima, Perú, 21 de marzo de 1991. Disponible en: http://www.sice.oas.org/trade/junac/decisiones/DEC284S.asp. Comisión del Acuerdo de Cartagena, CAC, Decisión 285 de 1991, normas para prevenir o corregir las distorsiones en la competencia generadas por prácticas restrictivas de la libre competencia, Lima, Perú, 21 de marzo de 1991. Disponible en: http://www.sice.oas.org/trade/junac/decisiones/ DEC285S.asp 
la normativa andina en estos países hasta cuando expidieran las normas nacionales correspondientes ${ }^{17}$.

El mérito de la Decisión 608/2005 fue el de haber conseguido una armonización mínima en el tema, la cual resultaba indispensable para avanzar y profundizar en el proceso de integración económica y el fortalecimiento de la defensa de la competencia.

A nuestro juicio, tanto en los procesos supranacionales como en los internos que se adelantan, sería conveniente aprovechar las experiencias foráneas en la materia pues estas podrían ilustrar las soluciones planteadas frente a problemas e interrogantes similares, en este caso, referidas a los modelos de aplicación de las normas de libre competencia y las funciones que cada uno de ellos cumple y los objetivos que se pueden alcanzar. Por supuesto, este proceso de "aprovechamiento" no puede implicar un calco automático o la imposición de modelos o sistemas (para los que no estamos aún preparados ni disponemos de los recursos necesarios), que pueden dar una apariencia de falsa modernidad a costa de la coherencia y la seguridad que deben brindar el ordenamiento jurídico, en general y el de libre competencia, en particular ${ }^{18}$.

\section{UNA VISIÓN GENERAL DE LA APLICACIÓN PÚBLICA de LAS NORMAS DE LIBRE COMPETENCIA}

La gran mayoría de los países latinoamericanos acogieron el modelo público o administrativo de aplicación de las normas de libre

17 Respecto a Bolivia, el artículo 49 de la Decisión 608/2005 y respecto a Ecuador, la Decisión 616/2005. Comisión de la Comunidad Andina, CAN, Decisión 608/2005, Normas para la protección y promoción de la libre competencia en la Comunidad Andina, Lima, Perú, 28 de marzo de 2005. Disponible en: http://intranet.comunidadandina.org/Documentos/decisiones/DEC608.doc. Comisión de la Comunidad Andina, CAN, Decisión 616/2005, entrada en vigencia de la Decisión 608 para la República del Ecuador. Disponible en: http://www.sice. oas.org/trade/junac/Decisiones/DEC616s.asp

18 En este sentido, compartimos las reflexiones de SPEncer Weber WALler, que señala: “(...) Neither system is entirely logical but neither jurisdiction has the luxury of writing on a clean slate. Most legal systems are a product of history, culture, inertia, and often random chance. For a new set of laws or procedures to accomplish their intended purpose, they must also be consistent with their jurisdiction's history and culture". SPEnCER WeBer Waller, Towards a Constructive Public-Private Partnership to Enforce Competition Law, 29 World Competition, Law and Economics Review, 3, 367-381, 375 (2006). Disponible en: http://papers.ssrn.com/sol3/ papers.cfm?abstract_id=905604 
competencia, siguiendo en esto el modelo de derecho continental materializado en el derecho comunitario europeo.

En este orden de ideas, los legisladores nacionales les confiaron la aplicación de esta normativa a entidades administrativas, a las cuales les asignaron la vigilancia de los mercados, el mantenimiento del orden público económico y la imposición de sanciones fundamentalmente económicas, acompañadas de órdenes de conducta o prohibiciones a los infractores. Bajo este sistema, la intervención de los jueces se limitó a la revisión y el control de las decisiones administrativas.

Como se expone a continuación, el modelo público o administrativo de aplicación de las normas de libre competencia fue acogido tanto en la legislación comunitaria como en la de cada uno de los países integrantes de la CAN (Bolivia, Colombia, Ecuador y Perú).

\section{A. El modelo comunitario andino}

Siguiendo las tradiciones jurídicas de sus Estados miembros, y el modelo de Derecho Comunitario Europeo anterior al Reglamento CE $1 / 2003^{19}$, la aplicación de las normas de libre competencia en la CAN adopta un modelo público o administrativo ${ }^{20}$.

Se hace necesario ahondar tanto en la regulación sustantiva de la libre competencia (conductas restrictivas y abusivas) como en su estructuración, y el sistema de aplicación de esta normativa para comprender las ventajas y problemas derivados de estos, lo que por supuesto implica realizar algunas observaciones sobre la Decisión 285/1991, y un estudio más detenido de la Decisión 608/2005 que la sustituyó ${ }^{21}$.

19 Consejo de la Unión Europea, Reglamento (CE) 1/2003 del Consejo, de 16 de diciembre de 2002, relativo a la aplicación de las normas sobre competencia previstas en los artículos 81 y 82 del Tratado, L1 Diario Oficial de las Comunidades Europeas, 4 de enero de 2003. Disponible en: http://eur-lex.europa.eu/LexUriServ/LexUriServ.do?uri=OJ:L:2003:001:0001:0025:ES:PDF

20 Tanto Colombia como Perú y en su momento Venezuela [que desde el 19 de abril de 2006 no hace parte de la CAN] consagraron en sus ordenamientos un sistema de aplicación de las normas de libre competencia que responde a características del "modelo público" que hemos descrito en la introducción de este artículo.

21 Como anteriores a las Decisiones 285/2001 y 608/2005 destacan sobre el tema de libre competencia las siguientes: (i) La Decisión 45/1971, sobre las normas para prevenir o corregir las prácticas que puedan distorsionar la competencia dentro de la subregión; (ii) la Decisión 230/1987 que establece las normas para prevenir o corregir las prácticas que puedan distorsionar la competencia dentro de la Subregión y sustituye la Decisión 45; (iii) las Decisiones 456 y 457 de 4 de mayo de 1999, que contienen normas para prevenir o corregir las distorsiones 
Un recorrido sobre los rasgos más notables del sistema anterior (Decisión 285/1991) y del vigente (Decisión 608/2005), pone en evidencia las similitudes de la normativa Andina con la regulación europea contenida en el Reglamento $17 / 1962^{22}$ (vigente hasta el año 2003), conforme al cual se confiaba con carácter exclusivo a la Comisión de la Comunidad Económica Europea la aplicación de las normas de competencia comunitarias artículo 85 y 86 del TCEE, actuales artículos 101 y 102 del TFUE y la concesión de excepciones de carácter singular.

La Decisión 285/1991, duramente criticada por la doctrina por establecer un ámbito subjetivo de aplicación demasiado restrictivo ${ }^{23}$, y por su inadecuada manera de regular los acuerdos colusorios y abusivos ${ }^{24}$, establecía un sistema de aplicación en el que la ins-

de la competencia generadas por prácticas de dumping o subvenciones en importaciones de productos originarios de países miembros de la Comunidad Andina; (iv) la Decisión 283 de 21 de marzo de 1991, que contiene normas para prevenir o corregir las distorsiones de la competencia generadas por prácticas de dumping o subsidios en importaciones de terceros países y (iv) la Decisión 284 que contiene normas para prevenir o corregir las distorsiones de la competencia generadas por restricciones a las exportaciones. Cristian Urrego-CAmargo cita como antecedente de la Decisión 285/1991, los artículos 93 y 94 del Acuerdo de Cartagena. Cristian Urrego-Camargo, El régimen de la libre competencia en la Comunidad Andina de Naciones (Tesis de grado, Manuel Guiller mo Sossa, dir., Universidad Externado de Colombia, Departamento de Derecho Comercial, 2007). También puede verse para una descripción general de la normativa andina de libre competencia anterior a la Decisión 608/2005, JORGE CAStro-Bernieri, La regulación de la competencia en la Comunidad Andina, 207 Gaceta Jurídica de la Unión Europea y de la Competencia, 49-67 (2000).

22 Consejo de la Comunidad Económica Europea, Reglamento 17/1962, normas de aplicación y de procedimiento de los artículos 81 y 82 del Tratado CE (vigente hasta 2003), conforme al cual se confiaba con carácter exclusivo a la Comisión Europea la aplicación de las normas de competencia comunitarias artículo 85 y 86 del TCEE, actuales arts. 101 y 102 del TFUE y la concesión de excepciones de carácter singular, 13 Diario Oficial de las Comunidades Europeas, 21 de febrero de 1962. Disponible en: http://eur-lex.europa.eu/legal-content/ES/ TXT/?uri=URISERV\%3A126042, http://www.wipo.int/edocs/lexdocs/laws/es/eu/eu19les.pdf

23 Artículos 2 y 6 de la Decisión 285/1991.

24 Se consideraba que el sistema de prohibición era inadecuado en cuanto a la prohibición de las conductas restrictivas, toda vez que exigía la prueba de los perjuicios causados a las empresas por la conducta anticoncurrencial para demandar su aplicación, con lo cual las normas actuaban a posteriori y no ex ante como ocurre en la mayoría de los sistemas jurídicos. En otros términos, las empresas carecían de un sistema preventivo de los daños antitrust. Respecto a este punto, nuestra opinión — como la de la mayoría de doctrina — es crítica: La exigencia de un "perjuicio a la industria" como supuesto para la aplicación de las normas, desdibuja por completo la naturaleza de las disposiciones antitrust y su finalidad de protección al interés público. Al respecto, es posible consultar las observaciones de RAMÓN GARCíA-GALLARDO \& María Dolores Domínguez-Pérez, La reforma de la norma de competencia en la Comunidad Andina, 20 Boletín Latinoamericano de Competencia, 44-53 (2005). Disponible en: http:// ec.europa.eu/competition/publications/blc/boletin_20_1_es.pdf. Asimismo, se criticaba que la Decisión 285/1991 no establecía una prohibición per se en relación con los denominados hard core cartels, con lo cual se dejaba en un mismo nivel las conductas que afectaban la libre competencia con una intensidad diferente. En nuestra opinión, esta falta de regulación en 
trucción y la decisión de los procedimientos por la infracción de las normas de libre competencia comunitarias correspondían de manera exclusiva a la Junta del Acuerdo de Cartagena (sustituida en 1997 por la Secretaría General ${ }^{25}$.

Bajo esta normativa, la función de las autoridades nacionales de competencia consideradas como organismos de enlace, se limitaba al desarrollo de actividades de colaboración en el suministro de pruebas e información, e igualmente al acopio de pruebas entre los productores, distribuidores, exportadores, importadores y consumidores que tuviesen interés en el desarrollo de la investigación.

El principal problema del modelo establecido por la Decisión 285/1991 fue la falta de herramientas de la Secretaría General para hacer efectivo el cumplimiento de las normas comunitarias de competencia. Este órgano comunitario carecía de facultades para obtener la colaboración de las empresas en el curso de las investigaciones y lograr una cooperación efectiva de parte de las autoridades nacionales. En consecuencia, la comparecencia al proceso e igualmente las actuaciones que se surtían dentro del mismo terminaban siendo actos potestativos de las empresas infractoras.

Adicionalmente, la Secretaría General tampoco disponía de las potestades necesarias para ordenar la práctica de medidas cautelares, ni para controlar la adopción de medidas estructurales, ni mucho menos para imponer a los infractores medidas disuasorias o sanciones económicas (multas). En realidad, como resultado del procedimiento, la Secretaría General únicamente podía adoptar como medida sancionadora, la de conceder al Estado en el que las empresas afectadas realizaban su actividad, la facultad de aplicar aranceles preferenciales, esto es autorizar como medida de naturaleza defensiva el incumplimiento de los acuerdos arancelarios

realidad no era un asunto particularmente grave, toda vez que en la mayoría de los ordenamientos jurídicos las normas básicas o estructurales de competencia regulan el tema a partir de una prohibición general que se acompaña de un mecanismo de excepción; con lo cual, la sanción de las conductas especialmente restrictivas se convierte en un asunto de adecuada interpretación de las normas. El problema en realidad era - y sigue siendo- la mala estructuración de las normas generales y la carencia de un sistema de excepción.

25 La Secretaría General se creó mediante el Protocolo de Trujillo de 1996 y entró en funcionamiento el 1 de agosto de 1997. Bolivia, Colombia, Ecuador, Perú y Venezuela, Protocolo Modificatorio del Acuerdo de Integración Subregional Andino o Acuerdo de Cartagena (Protocolo de Trujillo), Trujillo, Perú, 10 de marzo de 1996. Disponible en: http://www.sice. oas.org/trade/junac/carta_ag/Trujillo.asp 
celebrados en el marco de la Comunidad ${ }^{26}$. Al final, el remedio terminaba siendo mucho más lesivo para el proceso de integración y en realidad muy poco efectivo desde el punto de vista disuasorio. Estas falencias junto al escaso conocimiento de esta normativa por parte de las empresas fueron las principales causas de una exigua aplicación de la Decisión 285/199127. Solo cinco asuntos fueron sometidos al procedimiento seguido ante la Secretaría General ${ }^{28}$,

26 Artículo 16 de la Decisión 285/1991. “(...) La Secretaría General además de declarar la prohibición cuando determine la existencia de prácticas prohibidas, solo podía autorizar al gobierno del país, al que pertenece la industria afectada, reducir los aranceles a las importaciones de terceros países, respecto del bien objeto de la práctica. En otras palabras, solo se podían adoptar medidas de carácter comercial, y no se podían imponer sanciones pecuniarias". Ramón García-Gallardo \& María Dolores Domínguez-Pérez, La reforma de la norma de competencia en la Comunidad Andina, 20 Boletín Latinoamericano de Competencia, 44-53, 52 (2005). Disponible en: http://ec.europa.eu/competition/publications/blc/boletin_20_1_es.pdf

27 “[...] el diseño normativo adoptado principalmente con la decisión 285 , no produjo ningún resultado concreto. Deficiencias estructurales y garrafales errores conceptuales como la falta absoluta de dientes (ausencia de sanciones y facultades concretas de investigación) o el establecimiento de requisitos absurdos como la prueba del perjuicio o la amenaza del mismo a la industria nacional, contribuyeron de manera sensible para que después de 14 años esta decisión se despida sin dejar absolutamente ningún legado concreto. ¿Bien ida?”. JAVIER Cortázar-Mora, Decisión 608 de la Comunidad Andina: un paso adelante para el sistema antimonopolios de la región, 2 Revista Derecho Competencia, 2, 123-152, 125 (2006). Disponible en: https://centrocedec.files.wordpress.com/2010/06/4-decision.pdf

28 Los asuntos discutidos fueron los siguientes: (i) Asociación Colombiana de Industrias Plásticas (ACOPLÁSTICOS) contra la Empresa Petroquímica de Venezuela (PEQUIVEN), declarado sin lugar mediante la Resolución 326 de 15 de octubre de 1992: Junta del Acuerdo de Cartagena, JUNAC, Resolución 326, Solicitud de Colombia para la aplicación de la Decisión 285 a las prácticas de la empresa Pequiven de Venezuela, 15 de octubre de 1992. Disponible en: http:// www.comunidadandina.org/Documentos.aspx?GruDoc=43. (ii) Sociedad Mercantil Importadora de Azúcar de Venezuela S.A. contra las centrales azucareras venezolanas y colombianas, declarado sin lugar mediante la Resolución 420 de 19 de mayo de 1996: Junta del Acuerdo de Cartagena, JUNAC, Resolución 420, Investigación solicitada por la empresa IMEZUCAR, por supuestas prácticas restrictivas de la libre competencia, 19 de mayo de 1996. Disponible en: http://www.comunidadandina.org/Documentos.aspx?GruDoc=43. (iii) Empresa Polipropileno Biorientado del Ecuador contra las empresas Polipropileno del Caribe S.A. (PROPILCO) y Polipropileno de Venezuela S.A. (PROPILVEN), declarado sin lugar por la resolución 11 de 9 de septiembre de 1997, confirmada por la Resolución 24 del 13 de noviembre de 1997: Secretaría General de la Comunidad Andina, Resolución 11, Investigación solicitada por la empresa Polipropileno Biorientado del Ecuador, Cía. Ltda. (BOPP), sobre supuestas prácticas restrictivas de la libre competencia, 9 de septiembre de 1997. Disponibles en http://www. comunidadandina.org/Documentos.aspx?GruDoc $=08$. Secretaría General de la Comunidad Andina, Resolución 24, Recurso de Reconsideración presentado por la empresa BOPP del Ecuador Cía. Ltda., en contra de la Resolución 011 de la Secretaría General, 13 de noviembre de 1997. Disponibles en http://www.comunidadandina.org/Documentos.aspx?GruDoc=08. (iv) Gobierno de Bolivia contra la Empresa Colombiana del Llano S.A. en la que se declaró improcedente la petición del Gobierno de Bolivia mediante la Resolución 389 de 8 de mayo de 2000: Secretaría General de la Comunidad Andina, Resolución 389, por la cual se declara la improcedencia de la solicitud de inicio de investigación, por supuestas distorsiones en la competencia generadas por prácticas restrictivas a la libre competencia, interpuesta por el Gobierno de Bolivia, 8 de mayo de 2000. Disponible en: http://www.comunidadandina.org/ Documentos.aspx?GruDoc=08. Finalmente, (v) el asunto de la Confederación Nacional de 
de los cuales solo en uno se admitió la denuncia y se autorizó al Estado la toma de medidas correctivas en defensa de sus empresas ${ }^{29}$. Ante las continuas críticas y la escasa aplicación de la Decisión 285/1991, y considerando la creciente importancia y modernización de la protección de la competencia para los Estados integrantes de la Comunidad, con el apoyo de la Comisión Europea, se promovió la modernización de la normativa comunitaria, proceso este que concluyó con la aprobación de la Decisión 608/2005.

La nueva Decisión Andina - actualmente vigente - delimita claramente el ámbito objetivo y territorial de aplicación de sus disposiciones e introduce mejoras en la regulación de las conductas restrictivas (actos y acuerdos). Tratándose de la aplicación de las

\footnotetext{
Palmicultores y Empresas de Palma Aceitera del Perú y las empresas Industrial del Espino S.A., Industrial Alpamayo S.A., Alicorp S.A. y Ucisa S.A., contra los palmicultores colombianos (Fondo de Estabilización de Precios para el Palmiste, Aceite de Palma y sus Fracciones). Este último asunto fue resuelto mediante la Resolución 984 de 15 de diciembre de 2005, bajo la ya vigente Decisión 608/2005: Secretaría General de la Comunidad Andina, Resolución 984, Investigación iniciada mediante Resolución 892, al amparo de la Decisión 285, relativa a la solicitud de la Confederación Nacional de Palmicultores y Empresas de Palma Aceitera del Perú, y de las empresas Industrial del Espino S.A., Industrial Alpamayo S.A., Alicorp S.A. y Ucisa S.A. para la "....aplicación de medidas para corregir perjuicios causados por prácticas restrictivas a la libre competencia", 15 de diciembre de 2005. Disponible en: http:// www.comunidadandina.org/Documentos.aspx?GruDoc $=08$. Estos casos son mencionados por Ramón García-Gallardo \& María Dolores Domínguez-Pérez, La reforma de la norma de competencia en la Comunidad Andina, 20 Boletín Latinoamericano de Competencia, 44-53 (2005). Disponible en: http://ec.europa.eu/competition/publications/blc/boletin_20_1_es.pdf. Jorge Castro-Bernieri, La regulación de la competencia en la Comunidad Andina, 207 Gaceta Jurídica de la Unión Europea y de la Competencia, 49-67, 61-62 (2000).

29 Mediante la Resolución 984 de 15 de diciembre de 2005 se autorizó al gobierno del Perú a emplear una medida correctiva frente a las importaciones de manteca vegetal comestible elaborada a base de aceite de palma proveniente de Colombia. La medida tenía como límite temporal el plazo de un año y como límite material, de una parte, el valor de las compensaciones que los productores y los exportadores colombianos recibían del Fondo de Estabilización de precios y, de otra, la inexistencia de otras medidas con propósitos o fines idénticos. Aunque la resolución fue objeto del recurso de reconsideración, se confirmó por medio de la Resolución 1040, de 25 de julio de 2006, que declaró infundado el recurso y únicamente procedió a modificar la resolución inicial al extender la aplicación de las medidas correctivas a los vendedores. Secretaría General de la Comunidad Andina, Resolución 984, Investigación iniciada mediante Resolución 892, al amparo de la Decisión 285, relativa a la solicitud de la Confederación Nacional de Palmicultores y Empresas de Palma Aceitera del Perú, y de las empresas Industrial del Espino S.A., Industrial Alpamayo S.A., Alicorp S.A. y Ucisa S.A. para la "....aplicación de medidas para corregir perjuicios causados por prácticas restrictivas a la libre competencia", 15 de diciembre de 2005. Disponible en: http://www. comunidadandina.org/Documentos.aspx?GruDoc $=08$. Secretaría General de la Comunidad Andina, Resolución 1040, Recurso de Reconsideración contra la Resolución 984 presentado por el Gobierno de Colombia, la Federación Nacional de Cultivadores de Palma de Aceite de Colombia (Fedepalma) y la empresa Acegrasas S.A., 25 de julio de 2006. Disponible en: http://www.comunidadandina.org/Documentos.aspx?GruDoc $=08$
} 
normas antitrust ${ }^{30}$, la nueva Decisión mantiene el procedimiento público-administrativo, al tiempo que incluye importantes novedades para reforzar la actividad de la Secretaría General y permitir una aplicación más efectiva de las disposiciones de competencia subregional ${ }^{31}$.

Entre las novedades introducidas por la Decisión 608/2005 en el régimen de aplicación de las normas de libre competencia, destacan las siguientes: (i) Establece un conjunto de principios que orientan la aplicación de las normas comunitarias y el desarrollo de los procedimientos en caso de infracción ${ }^{32}$. (ii) Regula la participación de las autoridades nacionales de competencia en la fase de instrucción. (iii) Prevé la intervención dentro del procedimiento del Comité Andino de Defensa de la Libre Competencia (en adelante, CADC) ${ }^{33}$. (iv) Reglamenta las potestades tanto de las Autoridades Nacionales como de la Secretaría General para ordenar y practicar diligencias

30 La Decisión 608/2005 regula el tema en sus artículos 8 y 9 y diferencia entre acuerdos colusorios y abusivos. Toda vez que no hay pautas comunes sobre el alcance de la prohibición de los acuerdos colusorios, y dado el desbalance entre las experiencias de los Estados miembros, en nuestro concepto, sería esencial definir unas reglas comunes que orienten la interpretación y aplicación de estas normas para evitar divergencias, como en efecto lo ha hecho la Comisión con las diferentes comunicaciones por medio de las cuales se han expedido directrices, o se ha regulado y precisado el alcance de conceptos como "efectos sobre el comercio", "acuerdos de menor importancia", "cartas de orientación" entre otros muchos.

31 En efecto, los artículos 4 y 5 de la Decisión 608/2005 definen los ámbitos subjetivo, objetivo y territorial de aplicación de la normativa, a partir de los cuales se establecen y diferencian las competencias de la Secretaría General y de las autoridades nacionales. A estos efectos es necesario verificar si las conductas restrictivas se desenvuelven entre los supuestos previstos en los mencionados artículos para determinar si es aplicable la normativa comunitaria o, en cambio, deben aplicarse las normas nacionales y, en directa conexión con estos aspectos, definir la autoridad competente para conocer de la infracción.

Sobre las mejoras introducidas por la Decisión 608/2005, vale la pena destacar el hecho de que la norma comunitaria se preocupe por primera vez de la coherencia entre el derecho comunitario andino y los ordenamientos nacionales, y en tal sentido que permita que se ordenen y establezcan medidas para que las normas nacionales no impidan ni restrinjan la libre competencia en el mercado subregional (artículo 36). Una visión sobre las ventajas del nuevo régimen de la Decisión 608/2005 es la de María Clara Lozano, cuando afirma: "Es de esperarse que este nuevo sistema implique un importante intercambio de experiencias en materia de investigaciones y un flujo tanto de información como de formación entre las distintas autoridades de competencia (en particular de aquellas que cuentan con más experiencia hacia aquellas que no cuentan con ella). Igualmente es previsible un fortalecimiento de la ejecución de la nueva normativa andina en el marco subregional dado que los mecanismos previstos en ella se observan más eficientes y menos costosos para la autoridad supranacional, los gobiernos nacionales y los agentes económicos que resultaren interesados en un caso concreto". María Clara Lozano, La Decisión 608 de la CaN y sus implicaciones en Bolivia, 21 Boletín Latinoamericano de Competencia, 1, 42-50, 43 (febrero de 2006). Disponible en: http:// ec.europa.eu/competition/publications/blc/boletin_21_1.pdf

32 Artículo 3 de la Decisión 608/2005.

33 Artículo 38 de la Decisión 608/2005 y las demás que en él se mencionan. 
de exhibición de documentos, interrogatorios e inspecciones. (iv) Regula la facultad de la Secretaría General para imponer medidas correctivas y/o sancionadoras.

Conforme lo disponen las normas vigentes cuando la normativa aplicable al caso sea la andina, corresponde a la Secretaría General de la CAN conocer de la infracción, verificar la ilicitud de la conducta e imponer las consecuencias que de ello derivan. Para esto, debe adelantar un procedimiento sancionador — de carácter administrativo - del cual se destacan como rasgos fundamentales los siguientes:

a. El procedimiento puede ser iniciado tanto de oficio como a solicitud de las autoridades nacionales de competencia, las autoridades de integración, las personas naturales o jurídicas y las organizaciones de consumidores, entre otras (artículo 10).

b. El procedimiento se divide en dos grandes fases, una de investigación y otra de juzgamiento.

c. En el desarrollo de la fase de investigación colaboran a solicitud de la Secretaría General, las Autoridades Nacionales de los países donde tienen origen o realizan sus actividades económicas las empresas denunciadas y, de ser el caso, las de los Estados donde la conducta produce sus efectos (artículo 15) . $^{34}$.

d. Los aspectos más relevantes de la fase de investigación se definen de manera conjunta por la Secretaría y las Autoridades Nacionales mediante el llamado "plan de investigación”. La ejecución de este plan involucra la exhibición de documentos, la práctica de interrogatorios y de inspecciones que deben realizarse atendiendo lo dispuesto en el artículo 16 de la Decisión 608/2005 y las normas procesales del país miembro donde las diligencias tienen lugar.

e. Las pruebas, informes, dictámenes y demás diligencias adelantadas por las autoridades nacionales deben ser remitidos a la Secretaría General dentro de los 90 días siguientes, contados a partir de la notificación a las partes del plan de investigación (artículo 17). Durante el transcurso de este término y por 45 días

34 Conforme a esta regulación se hace evidente la preocupación y urgencia de que Ecuador expida una ley que regule el tema de la libre competencia en el ámbito nacional, designe una autoridad responsable en la materia y disponga de las normas procesales que permitan garantizar la aplicación de la normativa interna como de la andina. 
más (contados a partir del vencimiento del término anterior), la Secretaría General puede adelantar sus propias investigaciones siempre que ellas no interfieran y se adecúen con el plan de investigación acordado, solicitando si fuese necesario la remisión de información adicional tanto a las autoridades nacionales como a los gobiernos (artículos 18 y 19) ${ }^{35}$.

f. Expirados los términos anteriores, la Secretaría General elabora un informe que debe remitir al CADC con los alegatos de las partes, si se hubiesen presentado. El CADC tiene un plazo de 30 días hábiles desde la convocatoria para pronunciarse, so pena de que se entienda que consiente en el contenido del informe técnico de la Secretaría General.

g. Vencido el plazo, la Secretaría General emite una resolución en la que puede disponer la aplicación de medidas correctivas, como ordenar el cese de la práctica de forma inmediata o dentro de un lapso determinado, imponer condiciones u obligaciones, y ordenar el pago de multas al infractor si hay lugar a ello (artículo 34).

h. Por último, la Decisión 608/2005 establece que la ejecución de las medidas adoptadas por la Secretaría General estará a cargo de los gobiernos nacionales. En este caso, es lógico suponer que a estos efectos se deberán seguir las normas y procedimientos de carácter nacional.

El procedimiento que hemos descrito y, en general, el sistema de naturaleza pública o administrativa previsto para la aplicación de las normas antitrust andinas nos merecen varias observaciones y algunas sugerencias:

1. De conformidad con la Decisión 608/2005, la aplicación de las normas andinas corresponde a la Secretaría General, siempre que la conducta colusoria o abusiva se encuadre en los supuestos previstos en el artículo 5. Como corolario de la exclusividad establecida, ni las autoridades nacionales ni mucho menos los jueces nacionales pueden aplicar las normas comunitarias de libre competencia de forma directa, aunque aquellas sí pueden

35 Con base en las normas citadas supra se afirma que la fase de investigación del procedimiento se divide en dos etapas: la primera encomendada tanto a las autoridades nacionales como a la Secretaría General, y la segunda, solo a esta última, siempre que además haya circunstancias que exijan el recaudo de un mayor número de pruebas e información sobre el caso. 
intervenir en la constatación de la infracción durante la fase de investigación que está a su cargo.

2. Toda vez que la etapa de investigación a cargo de las autoridades nacionales es en realidad un procedimiento de carácter nacional, podrían suscitarse problemas procesales y de alteración de las condiciones de igualdad que deben presidir el desarrollo de esta etapa, en la medida en que la legislación de un país sea mucho más protectora y garantista que la de otro. En este sentido, consideramos que lo pertinente sería elaborar unas directrices comunes y vinculantes para todas las autoridades nacionales que fuesen aplicables al desarrollo de la fase de investigación ${ }^{36}$. De esta manera, se podría garantizar que esas autoridades sigan unos mismos principios y que garanticen unos derechos mínimos a las empresas u operadores económicos investigados.

3. Aunque el artículo 18 de la Decisión señala que “(...) las autoridades nacionales a cargo de la investigación y la Secretaría General estarán en coordinación permanente durante el período de la investigación", no se precisan cuáles son los mecanismos o instrumentos para ello ni las medidas tendientes a evitar que, por ejemplo, una prueba con idéntica finalidad se practique varias veces o se valore de manera distinta, lo que deja en evidencia los riesgos de dilaciones, contradicciones y desgastes innecesarios para las autoridades y las partes. Si bien el "plan de investigación" es una hoja de ruta importante para garantizar la coherencia de las acciones de ambas autoridades (comunitaria y nacional), creemos que es necesario reglamentar detalladamente los mecanismos de coordinación y de cooperación entre la Secretaría General y las autoridades nacionales.

36 En el sistema comunitario europeo, el procedimiento que sigue la Comisión se recoge en el Reglamento (CE) 773/2004. Por su parte, los procedimientos que siguen las autoridades nacionales de competencia de los Estados se someten a las normas procesales de orden nacional, cuya armonía se logra mediante la aplicación de los principios de efectividad y equivalencia que han sido desarrollados por la jurisprudencia del Tribunal de Justicia de las Comunidades Europeas. Comisión de las Comunidades Europeas, Reglamento (CE) 773/2004 de la Comisión, 7 de abril de 2004, relativo al desarrollo de los procedimientos de la Comisión con arreglo a los artículos 81 y 82 del Tratado CE, L 123 Diario Oficial de las Comunidades Europeas, 27 de abril de 2004. Disponible en: http://www.wipo.int/wipolex/es/text.jsp?file_id=181663. Comisión de las Comunidades Europeas, Reglamento (CE) 662/2008 de la Comisión, 30 de junio de 2008, por el que se modifica el Reglamento (CE) 773/2004 en lo que respecta al desarrollo de los procedimientos de transacción en casos de cártel (Texto pertinente a efectos del EEE), L 171 Diario Oficial de las Comunidades Europeas, 1 de julio de 2008. Disponible en: http:// eur-lex.europa.eu/legal-content/ES/TXT/?uri=CELEX\%3A32008R0622 
4. Nada se dice en la Decisión 608/2005 sobre la competencia de la Secretaría General cuando un asunto está siendo objeto de uno o varios procedimientos de orden nacional, ni se regulan tampoco los efectos que en estos casos tendría la asunción de competencias por parte de la autoridad andina. En otras palabras, no se regula el principio de primacía o prevalencia de la competencia de la autoridad supranacional, que en nuestra opinión estaría plenamente justificado y sería necesario respecto de aquellas conductas que claramente afecten el funcionamiento del mercado subregional.

5. Resulta bastante compleja la aplicación de las normas andinas a las empresas ubicadas en terceros Estados cuyas conductas han producido efectos en dos o más países miembros de la CAN. En estos casos, el desarrollo de la etapa de investigación está condicionado a la existencia de pactos de cortesía positiva, o a la celebración de acuerdos de derecho internacional privado que regulen el tema. Se trata en consecuencia de un punto que a futuro deberá solventarse mediante acuerdos entre la CAN y otros organismos subregionales y comunitarios. Este aspecto es especialmente relevante, dado que hay una gran probabilidad de que las conductas anticompetitivas tengan origen en terceros Estados, en particular que surjan producto de conductas de empresas multinacionales que entran en los mercados andinos y que buscan proteger sus filiales, y por esta vía sus intereses económicos ${ }^{37}$.

6. Hay múltiples vacíos en el procedimiento que se sigue ante la Secretaría General y que en nuestra opinión ameritarían una reglamentación de carácter supranacional, bien por medio de otra Decisión o de Directrices e Instrucciones de este órgano. Entre otros, se debería regular: (i) La intervención de terceros en el procedimiento. (ii) La impugnación de los actos o las decisiones de trámite que tienen lugar en el curso del proceso, como el plan

37 Este problema está anunciado en la nueva Ley Orgánica de Regulación y Control del Poder de Mercado, de Ecuador, que en su artículo 2 referente al ámbito de aplicación, afirma: “(...) a las personas naturales o jurídicas, públicas o privadas, nacionales y extranjeras, con o sin fines de lucro, que actual o potencialmente realicen actividades económicas en todo o parte del territorio nacional, así como los gremios que las agrupen, y las que realicen actividades económicas fuera del país, en la medida en que sus actos, actividades o acuerdos produzcan o puedan producir efectos perjudiciales en el mercado nacional" (itálicas fuera de texto). 
de investigación, el informe técnico de la Secretaría General o la decisión del CADC. (iii) La regulación de las vicisitudes que pueden tener lugar en la práctica de la exhibición de documentos, de las declaraciones o de las diligencias de inspección, así como la colaboración de las autoridades nacionales de los distintos Estados miembros en su práctica ${ }^{38}$.

Sobre estas observaciones generales y los vacíos que hemos identificado, consideramos conveniente que en las futuras reglamentaciones de los temas de libre competencia andina, se aproveche la experiencia europea respecto de los siguientes aspectos generales relativos al buen funcionamiento y el fortalecimiento del modelo público o administrativo de aplicación de las normas de libre competencia: (i) la expedición de directrices sobre conceptos o puntos esenciales de la aplicación de las normas de competencia ${ }^{39}$; (ii) la regulación detallada de los procedimientos ante la Comisión y de los mecanismos de control y coordinación de sus actividades con aquellas que están a cargo de las autoridades nacionales de competencia de los Estados miembros (en especial, sería importante aprovechar los avances sobre el funcionamiento de la Red de Autoridades de Competencia); y (iii) la operatividad del sistema de excepciones, que debería comprender no solo aquellas que se confieren por sectores o categorías de acuerdos, sino además la regulación de las exenciones singulares.

38 Aunque no se refieren strictu sensu a la aplicación de la normativa antitrust, también consideramos pertinente regular el contenido de los compromisos, la imposición de multas, su tipología, su graduación y su eventual aplicación a los altos directivos y administradores de las empresas infractoras. Esto es, que en general se adopten medidas tendientes a reforzar y brindar mayor transparencia al enforcement público.

39 Valga citar como ejemplo algunas comunicaciones que dentro del ordenamiento comunitario europeo regulan conceptos y trazan orientaciones de carácter transversal en el derecho de la competencia. Comisión Europea, Comunicación 2001 C 368/13 de 22 de diciembre de 2001, Comunicación de la Comisión relativa a los acuerdos de menor importancia que no restringen la competencia de forma sensible en el sentido del apartado 1 del artículo 81 del Tratado constitutivo de la Comunidad Europea (de minimis) (Texto pertinente a efectos del EEE), C 368 Diario Oficial de la Unión Europea, DOUE, 22 de diciembre de 2001. Disponible en: http://eur-lex.europa.eu/legal-content/ES/TXT/?uri=celex:52001XC1222(03). Comisión Europea, Comunicación 2004 C 101/07, 27 de abril de 2004, Comunicación de la Comisión - Directrices relativas al concepto de efecto sobre el comercio contenido en los artículos 81 y 82 del Tratado CE, C 101 Diario Oficial de la Unión Europea, DOUE, 27 de abril de 2004. Disponible en: http://eur-lex.europa.eu/legal-content/ES/TXT/?uri=celex:52004XC0427(06). Comisión Europea, Comunicación 2000 C 291/01, 13 de octubre de 2000, directrices relativas a las restricciones verticales, C 291 Diario Oficial de la Unión Europea, DOUE, 13 de octubre de 2000. Disponible en: http://eur-lex.europa.eu/legal-content/ES/TXT/?uri=celex:32000Y1013(01) 
Como último aspecto de esta visión general, es importante señalar que las normas andinas no hacen referencia a las consecuencias que en el ámbito jurídico-privado acarrea la transgresión de las normas de libre competencia ${ }^{40}$. Por consiguiente, surge la duda de si - a pesar de este vacío regulatorio - sería posible aplicar tales efectos (nulidad absoluta y responsabilidad civil) y quiénes podrían hacerlo.

A la luz de la evolución que ha tenido el tema, primero en Estados Unidos y más recientemente en la Unión Europea, consideramos que la omisión de la Decisión 608/2005 sobre los efectos civiles derivados de la infracción de las normas de libre competencia, no implica ni su negativa ni su exclusión.

Los efectos que en el ámbito del derecho privado derivan de los conductas colusorias o abusivas no encuentran fundamento directo en las disposiciones de libre competencia, aunque debiesen estar reconocidos en ellas; nacen en realidad de las normas y de los principios generales del derecho privado y, por ende, de los ordenamientos internos de los Estados miembros.

En efecto, la nulidad absoluta surge de las normas que establecen las consecuencias de la transgresión de los límites a la autonomía privada, y en concreto de las disposiciones que prohíben los acuerdos contrarios a las normas de orden público o normas imperativas, entre las que están las normas de libre competencia. La responsabilidad civil, por su parte, deriva de la infracción de las disposiciones que establecen el deber de reparar los daños ocasionados a consecuencia de las acciones u omisiones culposas o dolosas (infracción del naeminen ladere — responsabilidad extracontractual—) o de la infracción de un deber concreto adquirido en virtud de una relación negocial previa (responsabilidad contractual).

Comoquiera que estos efectos están regulados en el derecho civil de los Estados miembros e incluso, en algunos casos, en las propias normas de libre competencia nacionales, según lo veremos

40 Por regla general, los regímenes de libre competencia foráneos - tanto nacionales como supranacionales-suelen incluir junto a las cláusulas de prohibición de los acuerdos colusorios y abusivos, una o varias disposiciones que regulan la nulidad absoluta de este tipo de acuerdos e, igualmente, la responsabilidad civil de los infractores. En Europa, por ejemplo, el artículo 101.2 del TFUE establece la nulidad absoluta de los acuerdos restrictivos y la jurisprudencia del Tribunal de Justicia de las Comunidades Europeas, TJCE, reconoce la responsabilidad civil derivada de los daños ocasionados por estas conductas. 
más adelante, consideramos que hay bases para debatir sobre la intervención de los jueces nacionales en la aplicación de las normas comunitarias de competencia y la declaración de los efectos civiles derivados de su infracción.

En conclusión, aunque nada diga la Decisión 608/2005 sobre los efectos civiles, a nuestro juicio las víctimas de los comportamientos anticoncurrenciales pueden reclamar ante los jueces nacionales, conforme a la normativa de orden civil y de libre competencia, la declaración de la nulidad absoluta de los acuerdos colusorios y/o la responsabilidad civil de los infractores. Cuestión distinta es si para la declaración de estos efectos es imprescindible agotar el procedimiento ante las instancias comunitarias y, por lo tanto, disponer de una decisión previa sobre la ilicitud de la conducta, o si en cambio se admite la aplicación directa de la Decisión 608 de 2005 por parte de los jueces nacionales a efectos de la imposición de sanciones civiles.

Desde luego, la declaración de los efectos privados de la infracción y la protección de las víctimas tocan directamente con el tema relativo al establecimiento andino de un sistema de aplicación judicial de las normas de libre competencia comunitarias ${ }^{41}$. Frente a esta situación, consideramos necesario asumir una actitud prudente y crítica al momento de formular una recomendación en este sentido, pues el afán modernizador no puede convertirse en causa del caos regulatorio e institucional. No se trata de una negativa rotunda pues como lo explicaremos ad infra hay bases para sentar un modelo de private enforcement nacional. No obstante, hay que

41 Sobre la compatibilización entre las acciones de daños y el sistema público de derecho de la competencia, David Rosenberg y James P. Sullivan sostienen: "Coordinating public and private litigation and settlement decisions is thus crucial to the effective enforcement of antitrust laws. To achieve the optimal joint level of enforcement that maximizes social benefit from any system teaming public and private law enforcers, the coordination mechanism must not only assure that each enforcer makes the appropriately motivated and proportionate investment of resources and effort, but also that their respective efforts are properly synchronized and combined. The key is redesigning the antitrust enforcement mechanism to include a double-sided means of coordination. It is not enough to enable private enforcers to 'police' public enforcers by bringing supplemental class actions; there must be some mechanism for enabling, and properly encouraging, public enforcers to police private enforcers by preventing undesirable private actions. To this point, proposals for reform have not achieved this result". David Rosenberg \& James P. Sullivan, Coordinating Private Class Action and Public Agency Enforcement of Antitrust Law, 2 Journal of Competition Law and Economics, Oxford Press, 2, 159-187, 162 (2006). Disponible en: http://www.antitrustinstitute.org/files/rosenbergsullivan\%20paper_121220081708.pdf 
ser cuidadosos en la forma en que se implemente y desarrolle este modelo comunitario, pues la situación andina no es la misma que dio lugar en Europa a la aceptación de este nuevo sistema.

\section{La experiencia en el modelo público de aplicación de las normas de libre competencia}

Las experiencias respecto del funcionamiento del modelo público en cada país andino, en especial en Perú y Colombia, aconsejan que ellas sean el punto de partida para promover un nivel paritario de desarrollo del tema en los distintos Estados miembros. A partir de esto se podría profundizar en el grado de acción, de competencias y de poderes que se confían a las autoridades andinas y a las autoridades nacionales de competencia en cuanto a la aplicación de la Decisión 608/2005.

La comparación entre las autoridades nacionales que tienen a su cargo la aplicación de las normas de libre competencia en cada uno de los países andinos, la naturaleza de los procedimientos que siguen, las decisiones que pueden adoptar y la forma de su impugnación ponen en evidencia la prevalencia y la fuerza que tiene el modelo público de aplicación de las normas de libre competencia en los Estados integrantes de la $\mathrm{CAN}^{42}$.

42 Esta sinopsis se ha elaborado con base en la información disponible en las páginas web de las autoridades de competencia de Perú, Colombia, Bolivia y Ecuador e, igualmente, teniendo como base el artículo de JuAn David GutiérRez R., La legislación de competencia en América Latina y el Caribe: historia, vigencia, aplicación y reformas (Centro de Estudios de Derecho de la Competencia, Working paper 07-05, 2007). Disponible en: http://papers.ssrn.com/sol3/ papers.cfm?abstract_id=1023811. Se dejan fuera las normas relativas a la competencia desleal, aquellas que tienen un alcance limitado o restringido a sectores económicos específicos y las relativas al control de las concentraciones empresariales. El objetivo es, por tanto, más que hacer una mención completa y detallada de toda la legislación antitrust vigente en cada uno de los países andinos (para la cual se puede consultar el trabajo aquí citado), resaltar las normas generales y básicas así como el sistema previsto para su aplicación, con miras a demostrar la primacía del modelo público y las ventajas que hasta el momento ha arrojado su aplicación. 


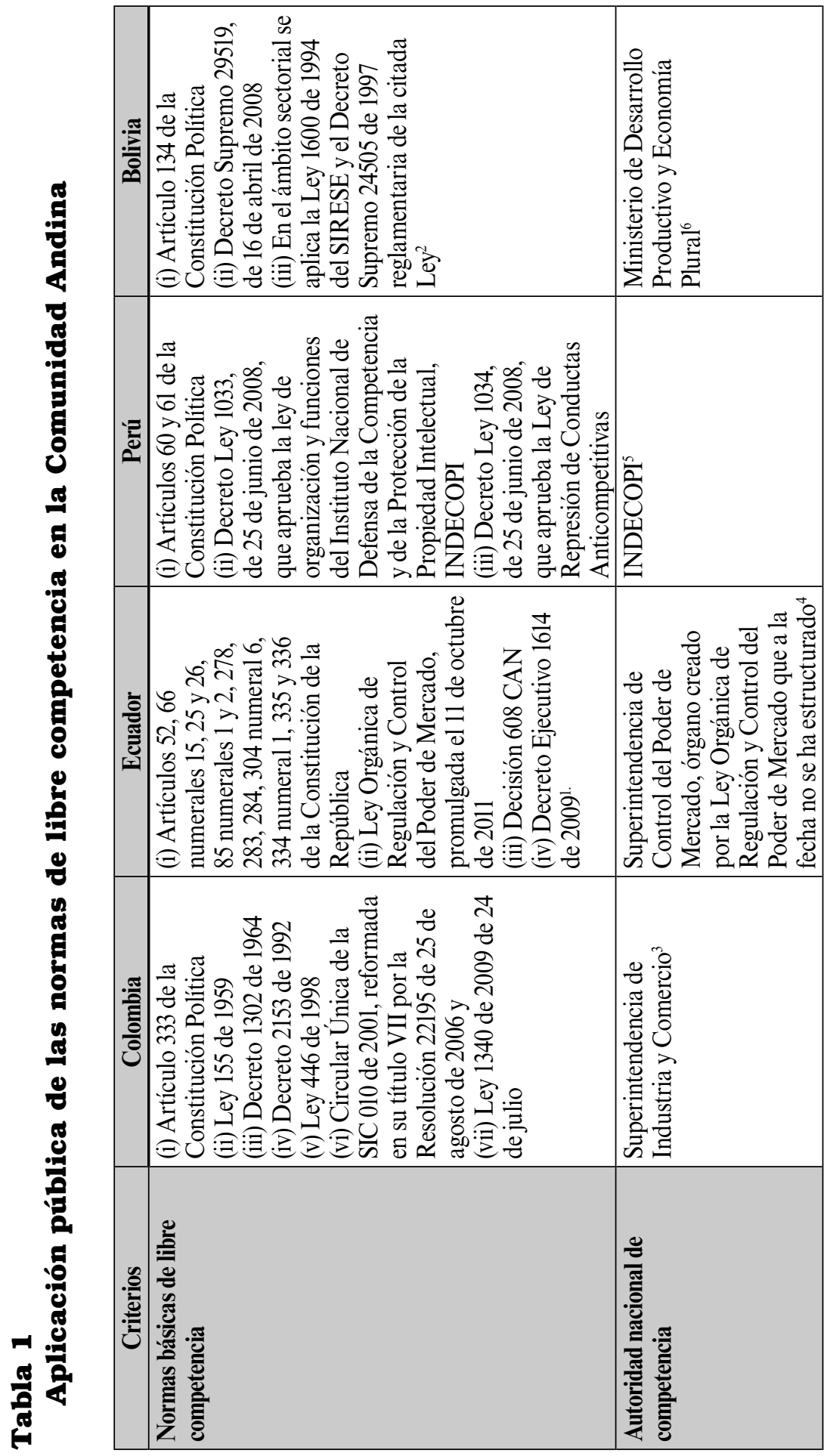




\begin{tabular}{|c|c|c|}
\hline صి & 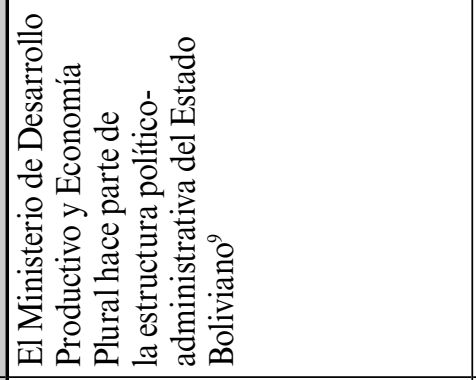 & 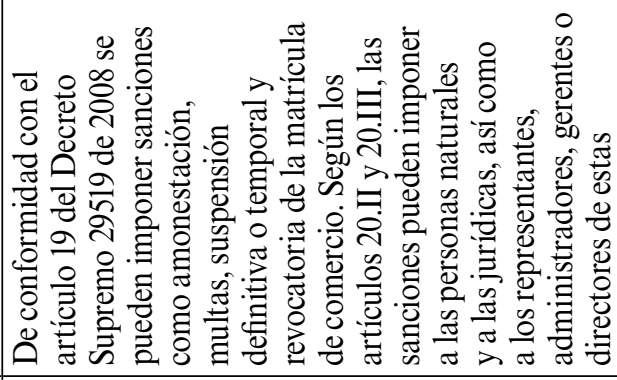 \\
\hline 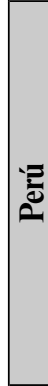 & 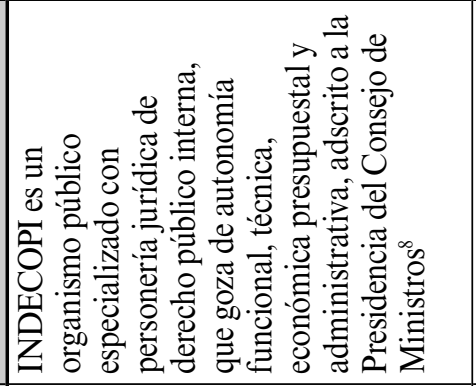 & 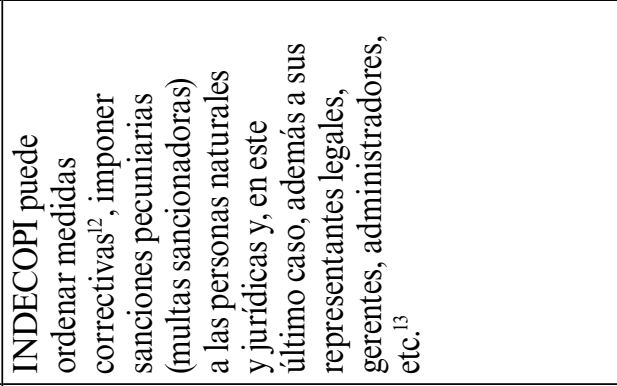 \\
\hline & 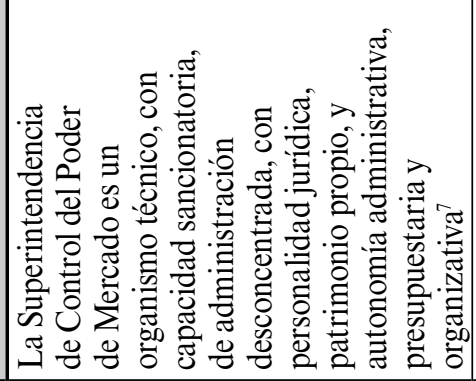 & 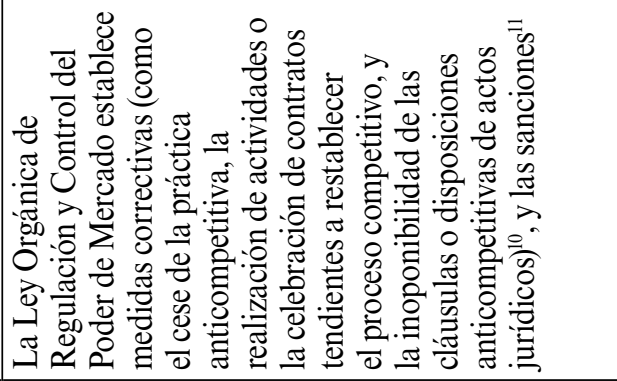 \\
\hline$\frac{.}{\frac{\pi}{\partial}}$ & 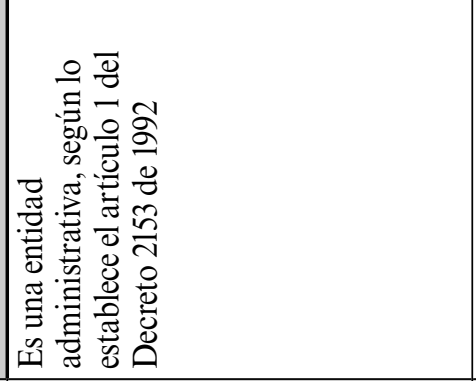 & 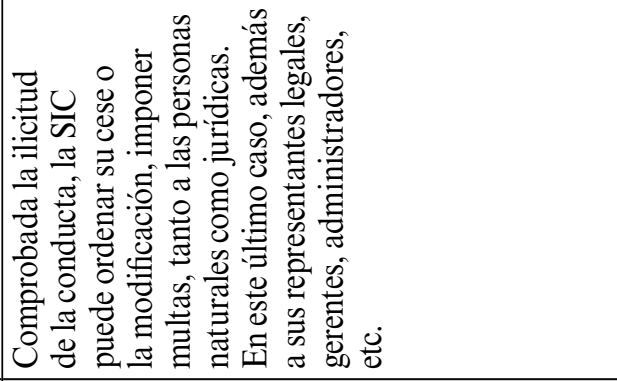 \\
\hline Uֶ, & 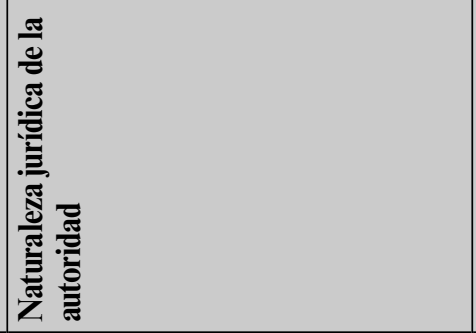 & 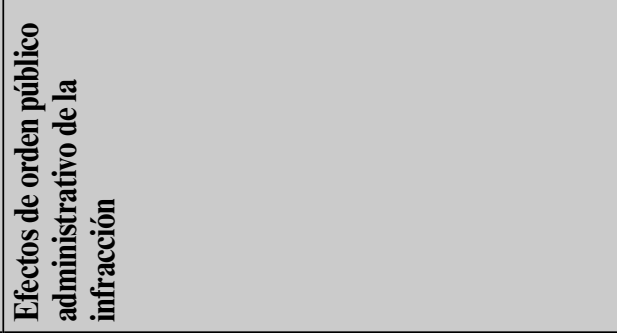 \\
\hline
\end{tabular}




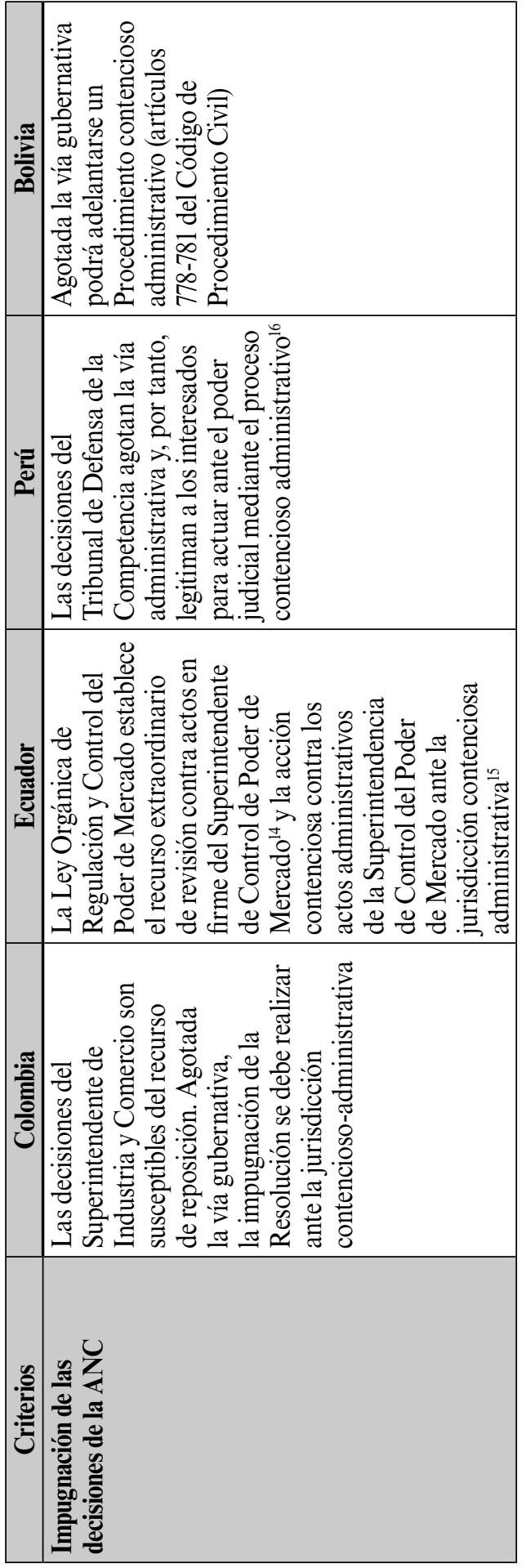

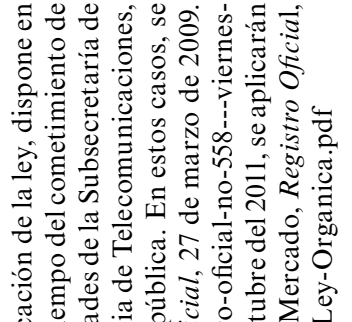

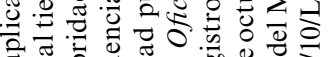
क्ष 耘 융.

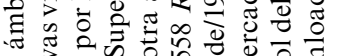
$\pi . \geq$ in

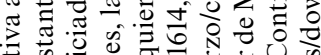

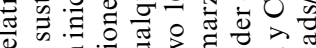

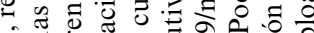

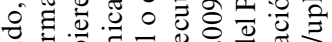
西

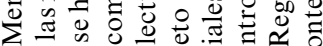

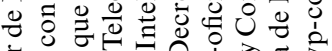

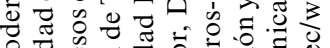

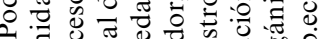
可

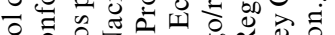
하음 : ○ 응

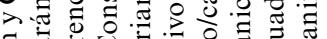

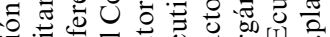

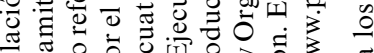

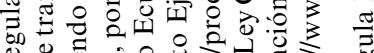

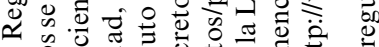
\% 일

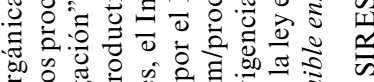
0 은 के के

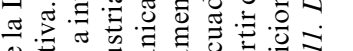
\& 푼. o

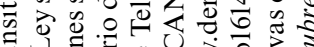
펀

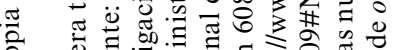

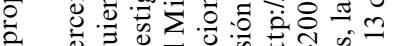

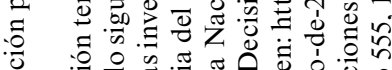
는 造

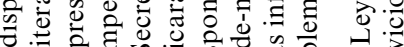

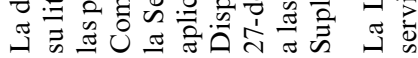




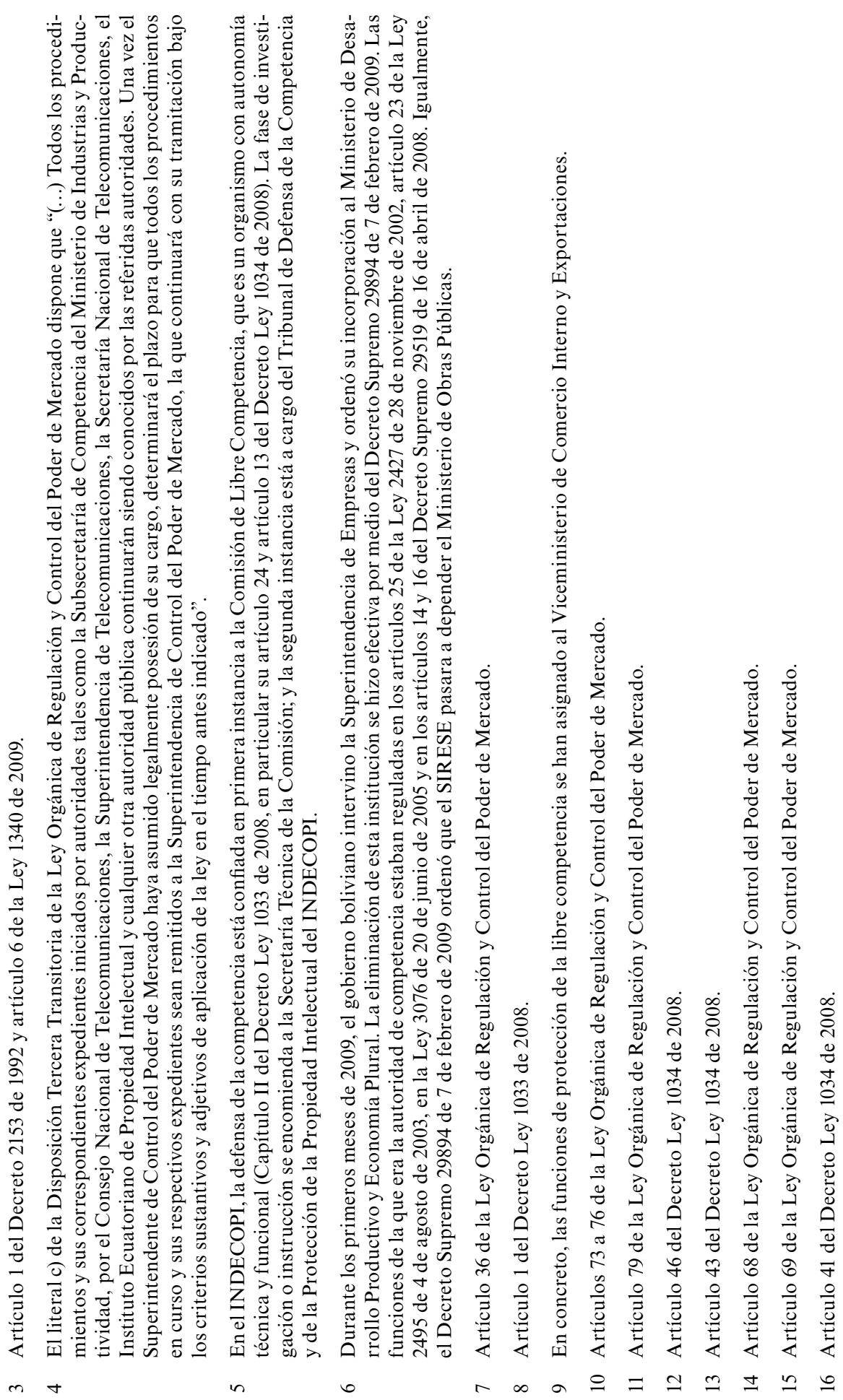




\section{CONCLUSIONES}

1. El modelo público o administrativo de aplicación de las normas de libre competencia fue acogido tanto en la legislación comunitaria como en la de cada uno de los países integrantes de la CAN (Bolivia, Colombia, Ecuador y Perú).

2. El análisis sobre la posible estructuración de un modelo privado en la Comunidad Andina NO puede hacerse a partir de las experiencias foráneas. En el estado actual de la integración y el desarrollo del derecho de la competencia comunitario, es necesario analizar las ventajas y los beneficios que hasta el momento ha arrojado el funcionamiento del modelo público y adoptar las medidas necesarias para su fortalecimiento y consolidación previa la estructuración y el desarrollo de un sistema en el que los jueces y las acciones de los particulares constituyen los principales supuestos de la aplicación de las normas de libre competencia.

3. Para los Estados miembros de la CAN, también consideramos necesario valorar las ventajas del modelo público y adoptar las medidas tendientes a su fortalecimiento. No obstante, dado que las normas nacionales ya han sentado las bases de un sistema de aplicación privada, estimamos que hay presupuestos suficientes para dar cabida a este nuevo modelo, disponiendo por supuesto de los elementos necesarios por medio de los cuales se garantice que las autoridades administrativas y judiciales podrán coexistir $\mathrm{y}$ funcionar de manera coherente. 


\section{BIBLIOGRAFíA}

\section{Libros}

Komninos, Assimakis, EC Private Antitrust Enforcement. Decentralised Application of EC Competition Law by National Courts (Hart Publishing, Oxford, Portland, Oregon, 2008).

\section{Colaboración en obras colectivas}

Rosales, Osvaldo, Integración regional: propuestas de renovación, en Paradojas de la Integración en América Latina y el Caribe, 33-66 (Josette Altmann, Francisco Rojas-Aravena, eds., Facultad Latinoamericana de Ciencias Sociales, FLACSO, Organización de Naciones Unidas, ONU, Comisión Económica para América Latina y el Caribe, CEPAL, Fundación Carolina de España, Siglo XXI Editores, 2008).

\section{Revistas}

CAStro-Bernieri, Jorge, La regulación de la competencia en la Comunidad Andina, 207 Gaceta Jurídica de la Unión Europea y de la Competencia, 49-67 (2000).

Celani, Marcelo \& Stanley, Leonardo, Defensa de la competencia en Latinoamérica: aplicación sobre conductas y estrategias, 28 Serie Estudios y Perspectivas, 61-64 (Organización de Naciones Unidas, ONU, Comisión Económica para América Latina y el Caribe, CEPAL, Oficina de Buenos Aires, Buenos Aires, Santiago de Chile, 2005. Disponible en: http://www.cepal.org/es/publicaciones/4851-defensade-la-competencia-en-latinoamerica-aplicacion-sobre-conductas-y

Cortázar-Mora, Javier, Decisión 608 de la Comunidad Andina: un paso adelante para el sistema antimonopolios de la región, 2 Revista Derecho Competencia, 2, 123152 (2006). Disponible en: https://centrocedec.files.wordpress.com/2010/06/4decision.pdf

García-Gallardo, Ramón \& Domínguez-Pérez, María Dolores, La reforma de la norma de competencia en la Comunidad Andina, 20 Boletín Latinoamericano de Competencia, 44-53 (2005). Disponible en: http://ec.europa.eu/competition/ publications/blc/boletin_20_1_es.pdf

González, Aldo \& Micco, Alejandro, Private versus Public Antitrust Enforcement: Evidence from Chile, 10 Journal of Competition Law \& Economics, 3, 691709. Disponible en: http://lacer.lacea.org/bitstream/handle/123456789/53161/ lacea2015_private_versus_public.pdf?sequence $=1$

Lande, Robert H. \& Davis, Joshua P., Benefits from Private Antitrust Enforcement: An Analysis of Forty Cases, 42 University of San Francisco Law Review, 879-918 (2008). Disponible en: http://papers.ssrn.com/sol3/papers.cfm?abstract_id=1090661

Lozano, María Clara, La Decisión 608 de la CAN y sus implicaciones en Bolivia, 21 Boletín Latinoamericano de Competencia, 1, $42-50$ (febrero de 2006). Disponible 
en: http://ec.europa.eu/competition/publications/blc/boletin_21_1.pdf

Marcos, Francisco, ¿Una política de competencia para la República de Ecuador?, 21 Boletín Latinoamericano de Competencia, 2, 29-39 (febrero de 2006). Disponible en: http://ec.europa.eu/competition/publications/blc/boletin_21_2.pdf

McAfee, Randolph Preston; Mialon, Hugo Marc \& Mialon, Sue H., Private v. Public Antitrust Enforcement: A Strategic Analysis, 92 Journal of Public Economics, 10/11, 1863-1875 (2008).

Ochoa-Urioste, Mauricio, Régimen General del Derecho de la Competencia en Bolivia -Decreto Supremo No. 29519_, 26 Boletín Latinoamericano de Competencia, 8-22 (2009). Disponible en: http://ec.europa.eu/competition/publications/blc/ boletin_26.pdf

Perilla-Castro, Carlos Andrés, Propuestas para la protección de la libre competencia ante los jueces civiles, 21 Boletín Latinoamericano de Competencia, 2, 20-28 (febrero de 2006). Disponible en: http://ec.europa.eu/competition/publications/ blc/boletin_21_2.pdf

Rosenberg, David \& Sullivan, James P., Coordinating Private Class Action and Public Agency Enforcement of Antitrust Law, 2 Journal of Competition Law and Economics, Oxford Press, 2, 159-187 (2006). Disponible en: http://www. antitrustinstitute.org/files/rosenberg-sullivan\%20paper_121220081708.pdf

Schinkel, Maarten Pieter, Effective Cartel Enforcement in Europe, 30 World Competition: Law and Economics Review, 4, 539-572 (2007) (Universiteit von Amsterdam, Amsterdam Center for Law \& Economics, Working Paper 2006-14, 2006). Disponible en: http://papers.ssrn.com/sol3/papers.cfm?abstract_id=948641

Waller, Spencer Weber, Towards a Constructive Public-Private Partnership to Enforce Competition Law, 29 World Competition, Law and Economics Review, 3, 367381 (2006). Disponible en: http://papers.ssrn.com/sol3/papers.cfm?abstract_ $\mathrm{id}=905604$

Wils, Wouter P. J., Should Private Antitrust Enforcement Be Encouraged in Europe?, 26 World Competition, Law and Economics Review, 3, 473-488 (2003). Disponible en: http://papers.ssrn.com/sol3/papers.cfm?abstract_id=1540006, https://www.researchgate.net/profile/Wouter_Wils/publication/228261623_ Should_Private_Antitrust_Enforcement_Be_Encouraged_in_Europe/ links/004635346539e943bc000000.pdf/download?version=vs

\section{Working paper}

Gutiérrez R., JuAn David, La legislación de competencia en América Latina y el Caribe: historia, vigencia, aplicación y reformas (Centro de Estudios de Derecho de la Competencia, Working paper 07-05, 2007). Disponible en: http://papers.ssrn. com/sol3/papers.cfm?abstract_id=1023811

Rüggeberg, Jacob \& Schinkel, Maarten Pieter, Consolidating Antitrust Damages in Europe: A Proposal for Standing in Line with Efficient Private Enforcement, 1-25 (Universiteit von Amsterdam, Amsterdam Center for Law \& Economics, Working Paper 2006-04, 2006). Disponible en: http://papers.ssrn.com/sol3/ papers.cfm?abstract_id=903282 
Segal, Ilya R. \& Whinston, Michael D., Public vs. Private Enforcement of Antitrust Law: A Survey, 1-17 (Stanford Law and Economics Olin, Working Paper 335, 2008). Disponible en: http://papers.ssrn.com/sol3/papers.cfm?abstract_id=952067

\section{Tesis de grado, ponencias}

Canovas, Pedro, Planteamientos de la integración. Evolución de la integración en Latinoamérica, en III Simposio Grupo de Estudios Jean Monnet, ponencia, Madrid, 7-8 de marzo de 2002, 19-35 (2002). Disponible en: http://pendientedemigracion. ucm.es/BUCM/cee/cjm/0201/0203.pdf

Urrego-Camargo, Cristian, El régimen de la libre competencia en la Comunidad Andina de Naciones (Tesis de grado, Manuel Guillermo Sossa, dir., Universidad Externado de Colombia, Departamento de Derecho Comercial, 2007).

\section{Tratados internacionales}

Bolivia, Colombia, Chile, Ecuador, Perú, Acuerdo de integración subregional andino (Acuerdo de Cartagena), Cartagena de Indias, Colombia, 26 de mayo de 1969. Disponible en: http://intranet.comunidadandina.org/Documentos/DBasicos/ DBasicol.doc

Bolivia, Colombia, Ecuador, Perú y Venezuela, Protocolo Modificatorio del Acuerdo de Integración Subregional Andino o Acuerdo de Cartagena (Protocolo de Trujillo), Trujillo, Perú, 10 de marzo de 1996. Disponible en: http://www.sice. oas.org/trade/junac/carta_ag/Trujillo.asp

Unión Europea, Tratado de Funcionamiento de la Unión Europea, TFUE, Roma, 25 de marzo de 1957. Disponible en: http://eur-lex.europa.eu/legal-content/ES/ $\mathrm{TXT} /$ ?uri $=$ celex $\% 3 \mathrm{~A} 12012 \mathrm{E} \% 2 \mathrm{FTXT}$

Unión Europea, Tratado de la Unión Europea, Maastricht, 7 de febrero de 1992, C191 Diario Oficial de las Comunidades Europeas, 29 de julio de 1992. Disponible en: http://europa.eu/eu-law/decision-making/treaties/pdf/treaty_on_european_ union/treaty_on_european_union_es.pdf

Unión Europea, Tratado de Lisboa, por el que se modifican el Tratado de la Unión Europea y el Tratado Constitutivo de la Comunidad Europea, en vigor desde el 1 de diciembre de 2009, C306 Diario Oficial de la Unión Europea, 17 de diciembre de 2007. Disponible en: https://www.boe.es/legislacion/enlaces/documentos/ue/ Trat_lisboa.pdf

\section{Normatividad internacional}

Bolivia, Decreto Supremo 24505, Reglamento a la Ley del Sistema de Regulación Sectorial, SIRESE, 21 de febrero de 1997. Disponible en: http://www.lexivox. org/norms/BO-DS-24505.xhtml

Bolivia, Decreto Supremo 29519, que regula la competencia y la defensa del consumidor frente a conductas lesivas, 16 de abril de 2008. Disponible en: http://www. 
autoridadempresas.gob.bo/marco-legal/decretos-supremos

Bolivia, Decreto Supremo 29894, Reorganización del Órgano Ejecutivo, de 7 de febrero de 2009. Disponible en: http://www.economiayfinanzas.gob.bo/index. php?opcion $=$ com_contenido\&ver $=$ contenido\&id $=894 \&$ id_item $=306 \&$ seccion $=230 \&$ categoria $=330$

Bolivia, Ley 1600 de 1994, Ley del Sistema de Regulación Sectorial (SIRESE), 28 de octubre de 1994. Disponible en: http://bolivia.infoleyes.com/shownorm. php?id=691

Bolivia, Ley 2427 de 2002, Ley del Bono Solidario, BONOSOL, 28 de noviembre de 2002. Disponible en: https://www.asfi.gob.bo/Portals/0/Leyes/Ley2427Bonosol.pdf

Bolivia, Ley 2495 de 2002, de Reestructuración Voluntaria, 4 de agosto de 2003. Disponible en: http://www.planificacion.gob.bo/uploads/marco-legal/2495_ley_ marco_juridico_alternativo_al_dispuesto_e.pdf

Bolivia, Ley 3076 de 2005, modificaciones a las Leyes de Bancos, del Bonosol y de procedimiento administrativo, 20 de junio de 2005. Disponible en: https://www. bcb.gob.bo/webdocs/normativa/leyes/Ley3076.pdf

Comisión de la Comunidad Andina, CAN, Decisión 456, normas para prevenir o corregir las distorsiones en la competencia generadas por prácticas de dumping en importaciones de productos originarios de Países Miembros de la Comunidad Andina, Lima, Perú, 4 de mayo de 1999. Disponible en: http://www.sice.oas.org/ trade/junac/decisiones/Dec456s.asp

Comisión de la Comunidad Andina, CAN, Decisión 457, normas para prevenir o corregir las distorsiones en la competencia generadas por prácticas de subvenciones en importaciones de productos originarios de Países Miembros de la Comunidad Andina, Lima, Perú, 4 de mayo de 1999. Disponible en: http://www.sice.oas.org/ trade/junac/decisiones/DEC457S.asp

Comisión de la Comunidad Andina, CAN, Decisión 608/2005, Normas para la protección y promoción de la libre competencia en la Comunidad Andina, Lima, Perú, 28 de marzo de 2005. Disponible en: http://intranet.comunidadandina.org/ Documentos/decisiones/DEC608.doc

Comisión de la Comunidad Andina, CAN, Decisión 616/2005, entrada en vigencia de la Decisión 608 para la República del Ecuador. Disponible en: http://www.sice. oas.org/trade/junac/Decisiones/DEC616s.asp

Comisión Europea, Comunicación 2000 C 291/01, 13 de octubre de 2000, directrices relativas a las restricciones verticales, C 291 Diario Oficial de la Unión Europea, DOUE, 13 de octubre de 2000. Disponible en: http://eur-lex.europa.eu/legalcontent/ES/TXT/?uri=celex:32000Y1013(01)

Comisión Europea, Comunicación 2001 C 368/13, 22 de diciembre de 2001, Comunicación de la Comisión relativa a los acuerdos de menor importancia que no restringen la competencia de forma sensible en el sentido del apartado 1 del artículo 81 del Tratado constitutivo de la Comunidad Europea (de minimis) (texto pertinente a efectos del EEE), C 368 Diario Oficial de la Unión Europea, DOUE, 22 de diciembre de 2001. Disponible en: http://eur-lex.europa.eu/legal-content/ES/ TXT/?uri=celex:52001XC1222(03)

Comisión Europea, Comunicación 2004 C 101/07, 27 de abril de 2004, Comunicación 
de la Comisión - Directrices relativas al concepto de efecto sobre el comercio contenido en los artículos 81 y 82 del Tratado CE, C 101 Diario Oficial de la Unión Europea, DOUE, 27 de abril de 2004. Disponible en: http://eur-lex.europa.eu/ legal-content/ES/TXT/?uri=celex:52004XC0427(06)

Comisión de las Comunidades Europeas, Reglamento (CE) 773/2004 de la Comisión, 7 de abril de 2004, relativo al desarrollo de los procedimientos de la Comisión con arreglo a los artículos 81 y 82 del Tratado CE, L 123 Diario Oficial de las Comunidades Europeas, 27 de abril de 2004. Disponible en: http://www.wipo.int/ wipolex/es/text.jsp?file_id=181663

Comisión de las Comunidades Europeas, Reglamento (CE) 662/2008 de la Comisión, 30 de junio de 2008, por el que se modifica el Reglamento (CE) 773/2004 en lo que respecta al desarrollo de los procedimientos de transacción en casos de cártel (Texto pertinente a efectos del EEE), L 171 Diario Oficial de las Comunidades Europeas, 1 de julio de 2008. Disponible en: http://eur-lex.europa.eu/legalcontent/ES/TXT/?uri=CELEX\%3A32008R0622

Comisión del Acuerdo de Cartagena, CAC, Decisión 230 de 1987, normas para prevenir o corregir las prácticas que puedan distorsionar la competencia dentro de la Subregión. Sustitución de la Decisión 45, Lima, Perú, 10-11 de diciembre de 1987. Disponible en: http://intranet.comunidadandina.org/Documentos/decisiones/ DEC230.doc

Comisión del Acuerdo de Cartagena, CAC, Decisión 283, normas para prevenir o corregir las distorsiones en la competencia generadas por prácticas de dumping o subsidios, Lima, Perú, 21-22 de marzo de 1991. Disponible en: http://www.sice. oas.org/antidumping/legislation/andina/dec283_s.asp

Comisión del Acuerdo de Cartagena, CAC, Decisión 284, normas para prevenir o corregir las distorsiones en la competencia generadas por restricciones a las exportaciones, Lima, Perú, 21 de marzo de 1991. Disponible en: http://www. sice.oas.org/trade/junac/decisiones/DEC284S.asp

Comisión del Acuerdo de Cartagena, CAC, Decisión 285 de 1991, normas para prevenir o corregir las distorsiones en la competencia generadas por prácticas restrictivas de la libre competencia, Lima, Perú, 21 de marzo de 1991. Disponible en: http:// www.sice.oas.org/trade/junac/decisiones/DEC285S.asp

Comisión del Acuerdo de Cartagena, CAC, Decisión 45 de 1971, normas para prevenir o corregir las prácticas que puedan distorsionar la competencia dentro de la subregión, Lima, Perú, 9-18 de diciembre de 1971. Disponible en: http://intranet. comunidadandina.org/Documentos/decisiones/DEC045.doc

Consejo de la Comunidad Económica Europea, Reglamento 17/1962, normas de aplicación y de procedimiento de los artículos 81 y 82 del Tratado CE (vigente hasta 2003), conforme al cual se confiaba con carácter exclusivo a la Comisión Europea la aplicación de las normas de competencia comunitarias artículo 85 y 86 del TCEE, actuales arts. 101 y 102 del TFUE y la concesión de excepciones de carácter singular, 13 Diario Oficial de las Comunidades Europeas, 21 de febrero de 1962. Disponible en: http://eur-lex.europa.eu/legal-content/ES/ TXT/?uri=URISERV\%3A126042, http://www.wipo.int/edocs/lexdocs/laws/es/ eu/eu191es.pdf

Consejo de la Unión Europea, Reglamento (CE) 1/2003 del Consejo, de 16 de diciembre 
de 2002, relativo a la aplicación de las normas sobre competencia previstas en los artículos 81 y 82 del Tratado, L1 Diario Oficial de las Comunidades Europeas, 4 de enero de 2003. Disponible en: http://eur-lex.europa.eu/LexUriServ/LexUriServ. do?uri=OJ:L:2003:001:0001:0025:ES:PDF

Ecuador, Constitución de la República del Ecuador, 449 Registro Oficial, 20 de octubre de 2008. Disponible en: http://www.asambleanacional.gov.ec/documentos/ constitucion_de_bolsillo.pdf

Ecuador, Decreto Ejecutivo 1614, 558 Registro Oficial, 27 de marzo de 2009. Disponible en: http://www.derechoecuador.com/productos/producto/catalogo/registrosoficiales/2009/marzo/code/19218/registro-oficial-no-558---viernes-27-de-marzode-2009\#No1614

Ecuador, Ley Orgánica de Regulación y Control del Poder del Mercado, Registro Oficial, Suplemento 555, 13 de octubre de 2011. Disponible en: http://www.planificacion. gob.ec/wp-content/uploads/downloads/2012/10/Ley-Organica.pdf

Junta del Acuerdo de Cartagena, JUNAC, Resolución 326, Solicitud de Colombia para la aplicación de la Decisión 285 a las prácticas de la empresa Pequiven de Venezuela, 15 de octubre de 1992. Disponible en: http://www.comunidadandina. org/Documentos.aspx?GruDoc $=43$

Junta del Acuerdo de Cartagena, JUNAC, Resolución 420, Investigación solicitada por la empresa IMEZUCAR, por supuestas prácticas restrictivas de la libre competencia, 19 de mayo de 1996. Disponible en: http://www.comunidadandina. org/Documentos. aspx?GruDoc $=43$

Parlamento Europeo, Consejo de la Unión Europea, Directiva 2014/104 del Parlamento Europeo, 26 de noviembre de 2014, relativa a determinadas normas por las que se rigen las acciones por daños en virtud del derecho nacional, por infracciones del derecho de la competencia de los Estados miembros y de la Unión Europea, L349 Diario Oficial de la Unión Europea, 5 de diciembre de 2014. Disponible en: http://eur-lex.europa.eu/legal-content/ES/TXT/?uri=CELEX\%3A32014L0104

Perú, Constitución Política, 30 de diciembre de 1993. Disponible en: http://spij. minjus.gob.pe/CLP/contenidos.dll?f=templates $\& \mathrm{f} n=$ default-constitucion. htm\&vid=Ciclope:CLPdemo

Perú, Decreto Legislativo 1033, que aprueba la ley de organización y funciones del Instituto Nacional de Defensa de la Competencia y de la Protección de la Propiedad Intelectual, INDECOPI, Diario Oficial El Peruano, 25 de junio de 2008. Disponible en: https://www.indecopi.gob.pe/documents/20182/143803/ d11033.pdf

Perú, Decreto Legislativo 1034, que aprueba la Ley de Represión de Conductas Anticompetitivas, Diario Oficial El Peruano, 25 de junio de 2008. Disponible en: https://www.indecopi.gob.pe/documents/51771/196578/d11034.pdf/66c0472e46de-4eb3-b872-7369c5279583

Perú, Decreto Legislativo 1205 de 2015, que modifica el Decreto Legislativo 1034 de 2008, que aprueba la ley de represión de conductas anticompetitivas, Diario Oficial El Peruano, 23 de setiembre de 2015. Disponible en: http://www.elperuano.com.pe/ NormasElperuano/2015/09/23/1290959-5.html

Perú, Decreto Ley 701 de 1991, eliminan las prácticas monopólicas, controlistas y 
restrictivas de la libre competencia, 5 de noviembre de 1991, Diario Oficial El Peruano, 7 de noviembre de 1991. Disponible en: http://www.sice.oas.org/compol/ natleg/Peru/701.asp

Secretaría General de la Comunidad Andina, Resolución 1040, Recurso de Reconsideración contra la Resolución 984 presentado por el Gobierno de Colombia, la Federación Nacional de Cultivadores de Palma de Aceite de Colombia (Fedepalma) y la empresa Acegrasas S.A., 25 de julio de 2006. Disponible en: http://www.comunidadandina.org/Documentos. aspx?GruDoc $=08$

Secretaría General de la Comunidad Andina, Resolución 11, Investigación solicitada por la empresa Polipropileno Biorientado del Ecuador, Cía. Ltda. (BOPP), sobre supuestas prácticas restrictivas de la libre competencia, 9 de septiembre de 1997. Disponibles en http://www.comunidadandina.org/Documentos. aspx?GruDoc $=08$

Secretaría General de la Comunidad Andina, Resolución 24, Recurso de Reconsideración presentado por la empresa BOPP del Ecuador Cía. Ltda., en contra de la Resolución 011 de la Secretaría General, 13 de noviembre de 1997. Disponibles en http://www.comunidadandina.org/Documentos.aspx?GruDoc $=08$

Secretaría General de la Comunidad Andina, Resolución 389, por la cual se declara la improcedencia de la solicitud de inicio de investigación, por supuestas distorsiones en la competencia generadas por prácticas restrictivas a la libre competencia, interpuesta por el Gobierno de Bolivia, 8 de mayo de 2000. Disponible en: http:// www.comunidadandina.org/Documentos.aspx?GruDoc $=08$

Secretaría General de la Comunidad Andina, Resolución 984, Investigación iniciada mediante Resolución 892, al amparo de la Decisión 285, relativa a la solicitud de la Confederación Nacional de Palmicultores y Empresas de Palma Aceitera del Perú, y de las empresas Industrial del Espino S.A., Industrial Alpamayo S.A., Alicorp S.A. y Ucisa S.A. para la “....aplicación de medidas para corregir perjuicios causados por prácticas restrictivas a la libre competencia”, 15 de diciembre de 2005. Disponible en: http://www.comunidadandina.org/ Documentos.aspx?GruDoc $=08$

\section{Normatividad colombiana}

Colombia, Constitución Política, segunda edición corregida, 116 Gaceta Constitucional, 20 de julio de 1991. Disponible en: http://www.secretariasenado.gov.co/senado/ basedoc/constitucion_politica_1991.html

Colombia, Decreto 1302 de 1964, por la cual se reglamenta la Ley 155 de 1959, en armonía con los Decretos 1653 de 1960 y 3307 de 1963. Disponible en: http://www.sice. oas.org/compol/natleg/Colombia/dec1302.asp

Colombia, Decreto 2153 de 1992, por el cual se reestructura la Superintendencia de Industria y Comercio y se dictan otras disposiciones, 40.704 Diario Oficial, 31 de diciembre de 1992. Disponible en: http://www.secretariasenado.gov.co/senado/ basedoc/decreto_2153_1992.html

Colombia, Decreto 2897 de 2010, por medio del cual se reglamenta el artículo 7 de la 
Ley 1340 de 2009, 47.792 Diario Oficial, 5 de agosto de 2010. Disponible en: http:// www.alcaldiabogota.gov.co/sisjur/normas/Norma1.jsp?i=40098

Colombia, Decreto 1523 de 2015, por medio del cual se reglamenta el artículo 14 de la Ley 1340 de 2009 y se modifica el Capítulo 29 del Título 2 de la Parte 2 del Libro 2 del Decreto Único Reglamentario del Sector Comercio, Industria y Turismo, Decreto 1074 de 2015, sobre beneficios a las personas naturales y jurídicas que colaboren en la detección y represión de acuerdos restrictivos de la libre competencia, 49.575 Diario Oficial, 16 de julio de 2015. Disponible en: http:// www.alcaldiabogota.gov.co/sisjur/normas/Norma1.jsp?i=62539

Colombia, Ley 155 de 1959, por la cual se dictan algunas disposiciones sobre prácticas comerciales restrictivas, 30.138 Diario Oficial, 22 de enero de 1960. Disponible en: http://www.alcaldiabogota.gov.co/sisjur/normas/Norma1.jsp?i=38169

Colombia, Ley 446 de 1998, por la cual se adoptan como legislación permanente algunas normas del Decreto 2651 de 1991, se modifican algunas del Código de Procedimiento Civil, se derogan otras de la Ley 23 de 1991 y del Decreto 2279 de 1989, se modifican y expiden normas del Código Contencioso Administrativo y se dictan otras disposiciones sobre descongestión, eficiencia y acceso a la justicia, 43.335 Diario Oficial, 8 de julio de 1998. Disponible en: http://www. secretariasenado.gov.co/senado/basedoc/ley_0446_1998.html

Colombia, Ley 1340 de 2009, por medio de la cual se dictan normas en materia de protección de la competencia, 47.420 Diario Oficial, 24 de julio de 2009. Disponible en: http://www.secretariasenado.gov.co/senado/basedoc/ley_1340_2009.html

Colombia, Superintendencia de Industria y Comercio, Circular Única de la SIC 010 de 2001, 44.511 Diario Oficial, 6 de agosto de 2001. Disponible en: http://www.sic. gov.co/drupal/circular-unica-sic

Colombia, Superintendencia de Industria y Comercio, Resolución 22195 de 25 de agosto de 2006. Disponible en: http://www.sic.gov.co/drupal/sites/default/files/ normatividad/Resolucion_22195_2006_0.pdf 